Torres, D. (2021). Aproximación a la Literatura de la Contabilidad Militar en la Primera y Segunda Guerra Mundial. Contaduría Universidad de Antioquia, 78, 35-74. Doi: https://doi. org/10.17533/udea.rc.n78a02

\title{
Aproximación a la Literatura de la Contabilidad Militar en la Primera y Segunda Guerra Mundial
}

Daniela Alejandra Torres Ruiz Universidad Santo Tomás - Bogotá danielatorresr@usantotomas.edu.co

Orcid: 0000-0002-8467-1252 
Aproximación a la Literatura de la Contabilidad Militar en la Primera y Segunda Guerra Mundial Resumen: El presente trabajo tiene como propósito elaborar una revisión documental sobre la contabilidad militar en la Primera y Segunda Guerra Mundial, mostrando los aspectos y campos más importantes trabajados. Con base en lo anterior, se tomó la bibliografia existente relacionada con el periodo objeto de estudio, proveniente de revistas contables indexadas en bases de datos académicas, $y$ posteriormente se realizó un análisis documental acerca de las similitudes y diferencias entre los contenidos de los textos encontrados, lo cual, permitió categorizarlos en diferentes items. El análisis sugiere que áreas como lo son los costos, la auditoria y la tributación tuvieron cambios significativos durante este periodo, enriqueciendo la forma en la que los procesos productivos, los pagos, los registros contables y las contrataciones de personal fueron reconocidos dentro de las empresas, y cambiando la forma en la que se llevaban a cabo, evidenciando la evolución de la contabilidad de la época.

Palabras clave: Contabilidad Militar, Primera Guerra Mundial, Segunda Guerra Mundial, aportes a la Contabilidad, evolución de la Contabilidad.

\title{
An approximation to Military Accounting Literature in World War I and II
}

Abstract: The aim of the present work is to carry out a documentary review on military accounting during World War I and II, showing the most important aspects and areas addressed. Based on the above, the existing bibliography related to the study period was taken from accounting journals indexed in academic databases, and a documentary analysis was subsequently carried out on the similarities and differences between the contexts of the texts found, which allowed to categorize them into different items. The analysis suggests that areas such as costs, auditing and taxes underwent significant changes during this period, thereby enriching the way in which productive processes, payments, accounting records and staff hiring were recognized within the companies, and changing the way in which they were conducted, thus evidencing the evolution of accounting in that period.

Keywords: Military Accounting, World War I, World War II, Contributions to Accounting, Evolution of Accounting.

\begin{abstract}
Aproximação à Literatura da Contabilidade Militar na Primeira e Segunda Guerra Mundial
Resumo: Este trabalho tem como intuito a elaboração de uma revisão documental sobre a contabilidade militar na Primeira e Segunda Guerra Mundial, mostrando os aspectos e campos mais importantes trabalhados. Com base no anterior, tomou-se a bibliografia existente relacionada com o periodo objeto de estudo, proveniente de revistas contábeis indexadas em bases de dados acadêmicas, e posteriormente realizou-se uma análise documental sobre as semelhanças e diferenças entre os conteúdos dos textos encontrados, o que permitiu categorizá-los em diferentes itens. A análise sugere que áreas como os custos, a auditoria e a tributação tiveram mudanças significativas durante este periodo, enriquecendo a maneira na que os processos produtivos, os pagamentos, os registros contábeis e as contratações de pessoal foram reconhecidos dentro das empresas, e mudando a maneira na que se implementam, evidenciando a evolução da contabilidade da época.

Palavras chave: Contabilidade Militar, Primeira Guerra Mundial, Segunda Guerra Mundial, Aportes à contabilidade, Evolução da contabilidade.
\end{abstract}

Un rapprochement de la littérature de la comptabilité militaire de la Première et de la Seconde Guerres mondiales

Résumé: Cette étude a pour but d'élaborer une revue documentaire sur la comptabilité militaire dans la Première et la Seconde Guerres mondiales, montrant les aspects et les domaines travaillés les plus importants. La bibliographie existante relative à la période considérée a été tirée de revues comptables indexées dans des bases de données académiques. Une analyse documentaire a ensuite été réalisée sur les similitudes et les différences entre les contenus des textes trouvés, ce qui a permis de les classer en différents éléments. L'analyse faite suggère que des domaines tels que les coûts, l'audit et la fiscalité ont connu des changements significatifs au cours de cette période, enrichissant la façon dont les processus de production, les paiements, les registres comptables et les recrutements de personnel ont été reconnus au sein des entreprises. Du même, la façon dont ils ont été effectués a changé, mettant en évidence l'évolution de la comptabilité de l'époque.

Mots-clés: Comptabilité militaire, Première Guerre mondiale, Seconde Guerre mondiale, Contributions à la comptabilité, Évolution de la comptabilité. 


\title{
Aproximación a la Literatura de la Contabilidad Militar en la Primera y Segunda Guerra Mundial
}

\author{
Daniela Alejandra Torres Ruiz \\ https://doi.org/10.17533/udea.rc.n78a02
}

Primera versión recibida en julio de 2020 - Versión aceptada en enero de 2021

\section{Introducción}

El presente trabajo tiene como objetivo analizar los desarrollos de la contabilidad bélica en materia de investigaciones durante la Primera y la Segunda Guerra Mundial. De forma más específica, se pretende hacer un análisis documental de los textos que tratan sobre los avances en materia contable desde lo bélico. Para esto, es necesario hacer un análisis sobre las categorías trabajadas por los diversos autores y analizar las similitudes y diferencias que cada texto ofrece.

La contabilidad bélica es una nueva subrama de la nueva historia de la contabilidad, la cual tiene una amplia conceptualización, puesto que la mayoría de autores no tiene una definición única para esta. Sin embargo, es importante resaltar que surgió hace pocos años, con el auge de la nueva historia de la contabilidad. Al respecto, una definición concreta para esta nueva forma de contabilidad sería: la medición, el análisis y el registro de las partidas que las fuerzas armadas de un país llevan a cabo, no sólo en el marco de la guerra, sino también en tiempos de paz, o entreguerras (IMECAF, 2012; Porto y Merino, 2009).

La importancia de estudiar este tema radica en el interés de los autores al querer saber cómo se llevaban las mediciones contables desde la Primera Guerra Mundial (comprendida entre 1914 y 1918), y la Segunda Guerra Mundial (comprendida entre 1939 y 1945), puesto que muchas veces los registros no estaban completos o existía desconocimiento general de parte de los empresarios sobre cómo aplicar la contabilidad. Incluso, saber cómo se debían pagar los impuestos que el Gobierno exigía como parte de la tributación ideada para financiar el conflicto. 
A nivel de Colombia, hay trabajos escasos que hacen referencia a este tema, debido a que pocos expertos en contabilidad han querido realizar una investigación de este tipo, como es el caso de Moreno (2014), abordando el periodo de guerras como un referente global acerca de la forma de llevar la contabilidad y cómo esta afectó en el desarrollo de los países y las empresas, debido en cierta parte a que no era de gran interés si no era para una formación meramente comercial (Rocha y Martínez, 2016), o el caso de Ariza (2017), quien muestra la inversión que ha realizado el Estado colombiano para terminar con el conflicto armado (una guerra que inició con las guerrillas hace más de cincuenta años) y cómo este ha beneficiado y afectado por igual a los principales actores del país (Estado, empresas y población civil).

Sin embargo, uno de los artículos que ofrece más elementos de estudio de las guerras en Colombia es el texto de Suárez llamado "El campo contable en el proceso de la independencia de Colombia (1780-1830)" (2011), en el que se hace un estudio exhaustivo acerca de la forma en la que se llevaba la contabilidad en los nueve periodos por los que el país pasó para obtener su independencia, mostrando una modificación en cuanto a la forma en la que se llevaba las ideas e instituciones por la época, haciendo que hubiera cambios completos (y otros parciales) en estos conceptos, y cómo la contabilidad jugó un papel clave al ayudar con elementos como la contabilización de bienes y de suministros. No obstante, y sin demeritar el trabajo que a nivel de Colombia se ha realizado, a nivel internacional se han hecho exhaustivas investigaciones, con autores interesados en estos eventos históricos como Hernández Esteve (2015), los cuales han abordado los conflictos bélicos más importantes a nivel de país o continente.

Cabe resaltar que frente al tema objeto de estudio, los autores que lo han abordado lo han hecho desde diferentes subtemas como los costos, las pensiones, la parte tributaria, entre otros; logrando establecer si estas investigaciones son pertinentes en cuanto al desarrollo de la contabilidad durante estos dos periodos de tiempo. Estos temas han comenzado a ser del interés de los autores que trabajan en contabilidad histórica (vertiente perteneciente a la nueva historia de la contabilidad), por lo cual se busca mostrar una recopilación de estos estudios donde muestren lo ya trabajado, y que permitan seguir realizando seguimientos a estos temas y generando motivaciones para que se investigue más a profundidad sobre la contabilidad militar en el periodo objeto de estudio, definiendo los principales aportes de la contabilidad en el campo militar en la primera y segunda guerra mundial.

Este documento está dividido en cuatro partes y un apéndice: En la parte uno se explicarán los antecedentes por los cuales la contabilidad bélica tomó fuerza para los autores, teniendo en cuenta la historia de la contabilidad y cómo se replanteó de una nueva manera, al mismo tiempo, se tomarán en cuenta los textos escritos por autores sobre la contabilidad militar en general. En la 
parte dos se explicará la metodología usada para la realización de este trabajo, junto a sus fases. En la parte tres se explicarán los resultados de cada categoría hallada, junto a una breve descripción de los textos, mostrando lo trabajado y sus principales conclusiones. Finalmente, en la parte cuatro se enunciarán las conclusiones más relevantes sobre el tema. El apéndice contiene anexos del documento como guías de referencia.

\section{Antecedentes históricos de la Contabilidad bélica}

La contabilidad históricamente ha evidenciado una serie de avances que le han permitido desarrollar nuevos temas de estudio, producto de las presiones y requerimientos del contexto. Sin embargo, no es sino hasta hace algunos años que varios investigadores apasionados por el tema, proponen una forma de llevar la historia contable, y esta misma forma de llevar la historia hace que una nueva vertiente se establezca como una nueva manera de contar y registrar los sucesos contables, estableciendo el patrón social en él. Estas vertientes son la historia tradicional y la nueva historia de la contabilidad.

La historia tradicional de la contabilidad tiene que ver más con un entorno social; según Fontana (1982): "Desde sus comienzos, en sus manifestaciones más primarias y elementales, la historia ha tenido siempre una función social, generalmente la de legitimar un orden (...), presentándose con la apariencia de una narración objetiva de acontecimientos concretos" (p. 15). Este tipo de historia, para Ríos (2009), es de tipo serial y cuantitativa en donde "lo mesurable se convertía en el dato a establecer por el historiador" (p. 99). En materia contable, Carmona (2004, citado por Quinche, 2006) habla de la historia tradicional como aquella que:

Se ha encargado de considerar importante las relaciones que la contabilidad tiene con el capitalismo, a través de la partida doble y la producción de información financiera (reportes) y de un modo evolucionista en el que las nuevas técnicas son mejores que las anteriores en el sentido en que responden a las nuevas necesidades externas. (p. 193)

Por otro lado, la denominada nueva historia de la contabilidad es "la historia de las mentalidades que trata de establecer una historia serial de las mentalidades, es decir, de las representaciones colectivas y de las estructuras mentales de las sociedades" (Gómez, 2012, p. 2). Esta vertiente tiene como objetivo hacer que se entienda la historia desde diferentes perspectivas (sociedad, economía, cultura, etc.), de forma coherente y homogénea. Con base en lo anterior, Hopwood (1987); Miller y Napier (1993), y Carmona (2004) (citados por Quinche (2006)), hablan sobre el tema:

Basa su estudio menos en el análisis de las prácticas contables aisladas -su evolución o progreso- y más en la interpretación de las implicaciones mutuas con el contexto dentro del cual tales prácticas son llevadas a cabo, así como en los intereses y las 
Torres, D. Aproximación a la Literatura de la Contabilidad Militar en la Primera y Segunda Guerra Mundial

instituciones que las hacen posibles. Además, otros análisis se basan en la forma semiótica en la que la contabilidad influye y es influenciada en un momento y un espacio específicos. (p. 195)

Teniendo en cuenta lo mencionado anteriormente, si bien existen dos vertientes históricas contables, la historia tradicional y la nueva historia, el hecho de que la nueva historia en el campo bélico comience a mostrar avances relevantes en cuanto a la exploración y realización de nuevos estudios, muestra un significativo avance en la materia; a pesar que en un principio la exploración y revisión de documentos contables y los avances desarrollados en cuanto a los elementos para representar la contabilidad no fuera de interés general (salvo para algunos estudiosos del tema), sino que comenzó a estar en auge a raíz de la nueva historia de la contabilidad.

Algunos estudiosos que decidieron apostarle al tema, como Hernández (2015), han realizado un estudio profundo de textos militares en general en cuanto a esta nueva rama contable. En su libro "Aproximación al estudio del pensamiento contable español", el autor comienza a explicar los trabajos realizados en la contabilidad militar, no solo aquellos que tuvieron un contexto internacional, sino también los encontrados en el contexto español. Un ejemplo de esto es el texto "The impact of naval experience on accounting in colonial Australia from 1788 to 1792" de Scorgie y Reiss (1997), el cual tenía su interés en la influencia que la contabilidad naval inglesa ejerció en la configuración del sistema contable establecido en la penitenciaría de Sydney Cove en 1788.

Además de este texto, el cual es el primero del cual el autor tiene conocimiento, se derivan otros textos que resumen, en gran parte, todo lo trabajado en la guerra, no solamente en la que se centrará este texto. Por ejemplo, Lemarchand (2002) publicó un artículo en el que se muestra cómo la contabilidad militar y las técnicas francesas en cuanto a la medición de costos indirectos, influyeron en la contabilidad de Francia. Igualmente, Cobbin (2009), revela en uno de sus artículos cómo existió un panel de expertos para controlar los gastos que el ejército australiano había tenido a raíz de una posible guerra con Japón y, por ende, por un aumento notable en el personal militar de esa época.

Dentro de estos autores, también se encuentra Funnell, quien ha sido el que más ha investigado y escrito artículos sobre contabilidad militar, y ha estimulado el interés de otros historiadores a investigar sobre el tema. Entre los principales trabajos de investigación que ha realizado se encuentran: "Accounting for War: Financial Control of the British Army 1846-1899" (2003), en el que explica la guerra que Inglaterra financió a Crimea, así como la Primera Guerra de Independencia de India. A pesar de explicar estos elementos, el libro no hace alusión a las cuestiones bélicas, sino a las tensiones en la segunda mitad del siglo XIX entre autoridades civiles y militares inglesas debido al control administrativo y financiero de las fuerzas armadas, al igual que la pelea 
entre los partidarios de las reglamentaciones y controles centralizados para tener mejor autonomía y eficiencia a la hora de administrar.

En cuanto al contexto español, el cual Hernández toma como referencia para sentar una base en cuanto a los trabajos desarrollados sobre las fuerzas armadas de tierra (surgido en el país hacia el siglo XV), hay varios trabajos del mismo autor que muestran cómo se adoptó la partida doble por parte de la corona española, como lo muestra el texto "Las cuentas de Fernán López del Campo, primer Factor General de Felipe II para los reinos de España (15561560). Contribución al estudio de la Contabilidad y de la Hacienda Pública en la España del siglo XVI" (1982), mostrando los avances en cuanto a la organización administrativa y financiera que manejaba Felipe II en cuanto a "captar, reunir, gestionar y situar en los lugares requeridos los fondos necesarios para financiar la guerra que contra él habían emprendido en 1556 el Papa Pablo IV y el rey Enrique II de Francia” (Hernández, 2015).

Fueron varios los autores que han desarrollado trabajos para este contexto en particular; sin embargo, todos han querido llegar al mismo fin: determinar cómo la contabilidad afectó de gran manera los procesos de la guerra. Uno de ellos es Dubet, quien en su artículo "Administrar los gastos de guerra: Juan Orry y las primeras reformas de Felipe V (1703-1705)" (2005), en el cual se habla acerca de las primeras reformas de los borbones en la administración de la guerra, teniendo como resultado la creación de dos instituciones (la Secretaría de Despacho de Guerra y la Tesorería Mayor de Guerra), concebidas como parte de reforma que Juan Orry realizó para devolver la conducta de la guerra al rey Felipe V, siendo innovadora (de forma prudente) y aceptable para la época.

Otro autor que destacó el trabajo de la contabilidad en la armada es Guzmán Raja, el cual en su artículo llamado "Normativa contable en la Armada Española durante el periodo 1700-1850: especial referencia a la administración de provisiones" (2006) muestra cómo la Real Armada Española sufrió cambios militares y administrativos, haciendo que la mayoría de procesos contables en esta época fueran rigurosos, especialmente en el tema de rendición de cuentas para cada legislación de reyes (como es el caso del Rey Felipe V) durante ciento cincuenta años, desde 1700 hasta 1850.

Finalmente, Gómez-Juárez de la Torre con su texto "Derechos reales en la contabilidad de la Real Armada. Estructura tributaria y particularidades de su aplicación sobre el autoconsumo en el departamento de Cartagena en 1779" (2018), el cual muestra cómo la Real Armada tuvo un mal manejo de las cuentas contables, poniendo varios tributos necesarios para el país como un gasto, en lugar de una cuenta acreedora e, incluso, se muestra cómo el contador cometió errores en cuanto a una compra de madera que había realizado el Cuerpo de Ingenieros de la Marina, presentando omisiones en cierto tipo de información y a una baja en los precios unitarios e importes de estas. 
De esta manera, se puede evidenciar que los trabajos elaborados sobre el tema han sido bastantes, aunque el interés hacia la contabilidad bélica de la primera y segunda guerra mundial tomó un auge especial entre los investigadores, debido a factores como la poca investigación realizada en este periodo de tiempo, los eventos y transacciones registrados que ocurrieron, entre otros. Los trabajos de Funnell (2003) (2005) (2006) (2008) (2011), Chwastiak (2007), Bujaki (2010), Cobbin (2009) (2010), Heier (2010), MayerSommer (2010) y Talbot (2010) en cuanto al contexto internacional, y algunos otros como González (2012), Blasco, Guzmán y Montoya (2011), Kuethe y Andrien (2018) y Torres (2013) en el contexto español, han sido estudios que han dado una visión general hacia la contabilidad militar, teniendo en cuenta que esta rama parcialmente explorada de la nueva historia de la contabilidad, ha intentado vislumbrar en los conocimientos que la parte civil le ha dado a la parte militar, y viceversa, al igual que las pugnas entre estos, mejorando e introduciendo nuevos y mejores métodos de registro y de control, al igual que el establecimiento de mejores procedimientos de contabilidad de costes (Hernández, 2015).

\section{Metodología}

La investigación propuesta se realizó bajo un enfoque cualitativo, a partir de las investigaciones que otros autores han hecho sobre la materia, con el objetivo de definir los principales aportes de la contabilidad en el campo militar durante la primera y segunda guerra mundial; lo propuesto anteriormente, se llevó a cabo mediante una revisión bibliográfica y el respectivo análisis documental de los archivos obtenidos sobre contabilidad militar en el periodo objeto de estudio (Hernández, Fernández y Baptista, 2010). El alcance de este estudio fue de tipo descriptivo-exploratorio, en cuanto se pretendía indagar sobre los principales aportes de la contabilidad en el campo militar en la primera y segunda guerra mundial. La presente investigación se desarrolló a partir de tres fases:

En la primera etapa, correspondiente a la identificación de fuentes, se realizó una revisión bibliográfica en la que se tomaron 30 artículos de diferentes revistas y libros académicos (todos estos ubicados en bases de datos virtuales, tales como: eLibro, EBSCOHost, Taylor \& Francis Online, Elsevier, JStor, De Computis, etc.). Las palabras de búsqueda usadas se encuentran en el Anexo A1.

En la segunda fase, que corresponde al análisis de contenido, el cual es el conjunto de pasos que permite representar el contenido y la forma del documento para facilitar su consulta (Clauso, 1993), se procedió a realizar una categorización de los principales temas a trabajar, permitiendo determinar las similitudes y diferencias entre estas categorías, para, finalmente, catalogarlas en una matriz de datos que permitió reconocer cada elemento de los textos 
trabajados. Para esto se tomó en cuenta la hipótesis, la metodología y las conclusiones de cada uno de los documentos trabajados.

Finalmente, en la tercera fase, se realizó una matriz primaria, en la que se define el título, el o los autores, la categoría a la que pertenece, la publicación en la que aparece (revista o libro), el año de publicación y una breve descripción de lo que trata el documento. Esta matriz se muestra en el Anexo A2.

\section{Resultados}

Siguiendo la metodología anteriormente propuesta, en la fase de identificación de fuentes se revisaron treinta textos provenientes de diversas revistas contables halladas en bases de datos online, como lo fueron Elsevier, eLibro, EBSCOHost, Taylor \& Francis Online, JStor, De Computis, O’Reily Safari, Universidad de Gakushuin, entre otras. En la siguiente figura, se ven reflejadas las revistas en las que se encontraron los textos objeto de estudio (en orden descendiente):

Figura 1: Revistas consultadas y número de publicaciones halladas

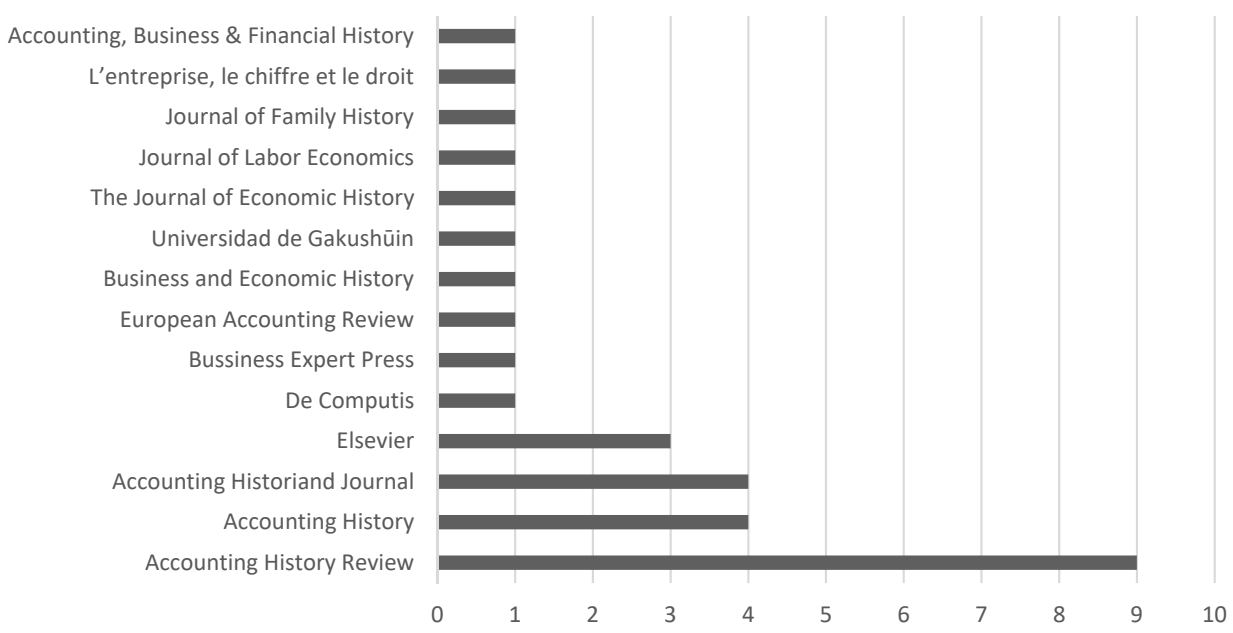

Fuente: Elaboración propia.

En la fase del análisis de contenido, teniendo en cuenta los textos hallados, se procedió a hacer una clasificación de cada documento contable según la temática de las lecturas. Esta categorización se realizó en base a lo que cada texto mostraba como su tema principal, y también por las similitudes que tienen con la contabilidad actual (como un ejemplo, se tomó en cuenta el avance que tuvo la auditoría al ser una parte mediadora en el final del conflicto, en el que Alemania tuvo que hacer una reparación integral a los 
países afectados; dándose esto por medio de controles que evolucionaron hasta los controles que conocemos hoy en día dentro de la auditoría). Según esto, se comprobó que uno de los elementos más trabajados en la bibliografía encontrada fueron los costos; bien fuesen los costos por manufactura o bien los costos por mantenimiento, entretenimiento, etc. (esto se explicará más adelante). Les siguen: la historia general de la contabilidad y la historia general de la contabilidad militar. La siguiente figura evidencia cada categoría trabajada y clasificada en orden descendente:

Figura 2: Revistas consultadas y número de publicaciones halladas

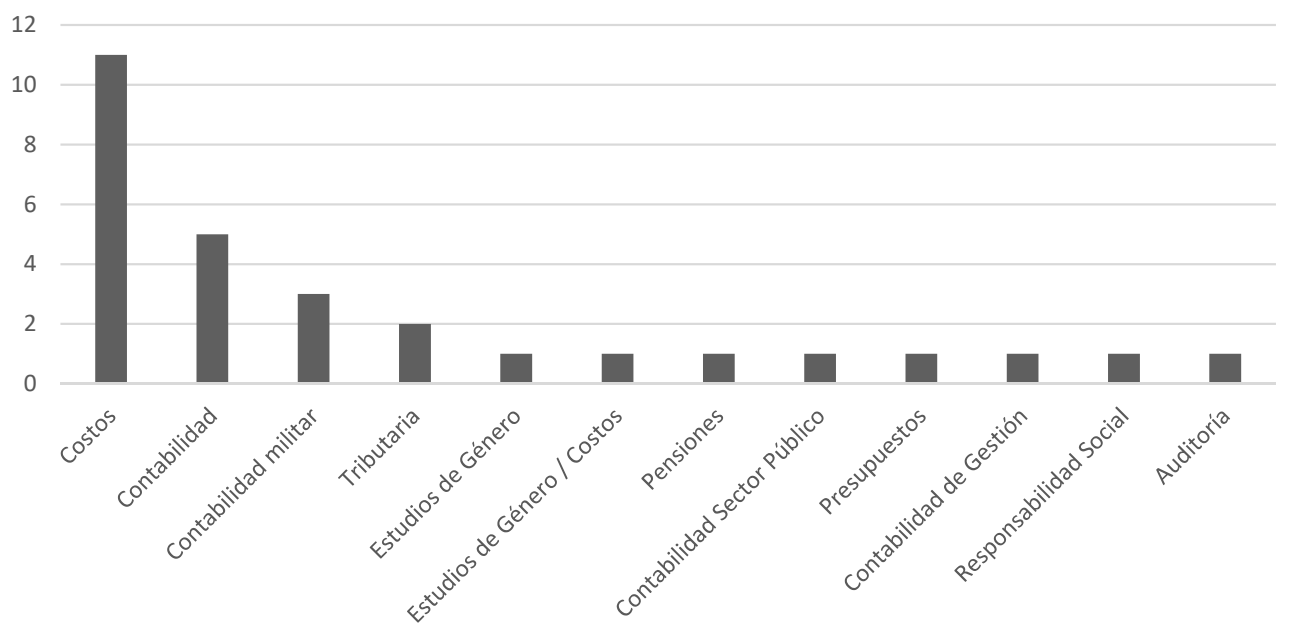

Fuente: Elaboración propia.

Finalmente, al establecerse la matriz primaria, se procedió a evaluar cada uno de los textos según su categoría, para así establecer diferencias y similitudes entre estos. Cabe resaltar que aquellos que cuentan con un solo texto serán descritos brevemente, sin posibilidad de establecer similitudes o diferencias. Sin embargo, y dado que también tienen elementos valiosos para comprender la contabilidad de la época, se hablará de sus aportes en el marco del periodo objeto de estudio. A continuación, se describirán las categorías establecidas en el presente estudio:

\section{IV.I. Costos}

Dentro de los costos, se encontraron trabajos relacionados con la forma en las que estas partidas fueron llevadas dentro de la contabilidad de las organizaciones, bien sea, debido a que se producían insumos para la guerra y debían ser catalogados como costos de producción, o existían otros costos que fueron implementados en las empresas con el fin de obtener un mejor 
rendimiento al final del año fiscal1 o del año contable². Dentro de esta categoría se encuentran los siguientes ítems de costos:

Figura 3: Listado de las diferentes subcategorías halladas en los textos de la categoría de costos

\begin{tabular}{|l|}
\hline \multicolumn{1}{|c|}{ Costos } \\
\hline - Determinación de precios (unitarios y totales) \\
- Costos de producción \\
- Costos de Capital \\
- Costos de Mantenimiento \\
- Costos de Entertenimiento \\
- Costeo Uniforme \\
- Costeo por Ubicación \\
- Contos de Nómina \\
- Costos por riesgos de guerra
\end{tabular}

Fuente: Elaboración propia.

La metodología trabajada en cada uno de los textos fue descriptivaexploratoria, debido a que se buscaba estudiar el fenómeno del registro de los costos dentro de las organizaciones. Un ejemplo claro de esto se encuentra en el texto "Accounting for war risk costs: management accounting change at Guinness during the First World War", en el que, a pesar de que la empresa, una cervecería pequeña que se encontraba ubicada en Dublín, tuviese problemas debido a situaciones como: restricciones gubernamentales en la primera guerra mundial o a que los barcos en los que se transportaba el licor hacia ciertas zonas fuesen atacados por alemanes, por resaltar algunas; la empresa contará con una contabilidad robusta, con monitoreos constantes realizados a las plantas de producción y con los costos indirectos de fabricación siendo registrados a cada centro de costo por igual (Quinn \& Jackson, 2014).

Las similitudes y diferencias entre los textos son los siguientes:

1 El año fiscal corresponde a un periodo de tiempo de doce (12) meses, en el que la empresa cumple con las obligaciones tributarias que le correspondan (Galán, 2017).

2 El año contable hace referencia al periodo que transcurre entre dos estados de situación general (ESG) de la empresa de forma consecutiva, tiempo en el cual esta cumple con su objeto social (Pedrosa, 2017). 
Torres, D. Aproximación a la Literatura de la Contabilidad Militar en la Primera y Segunda Guerra Mundial

Tabla 1: Similitudes y diferencias de la categoría de costos

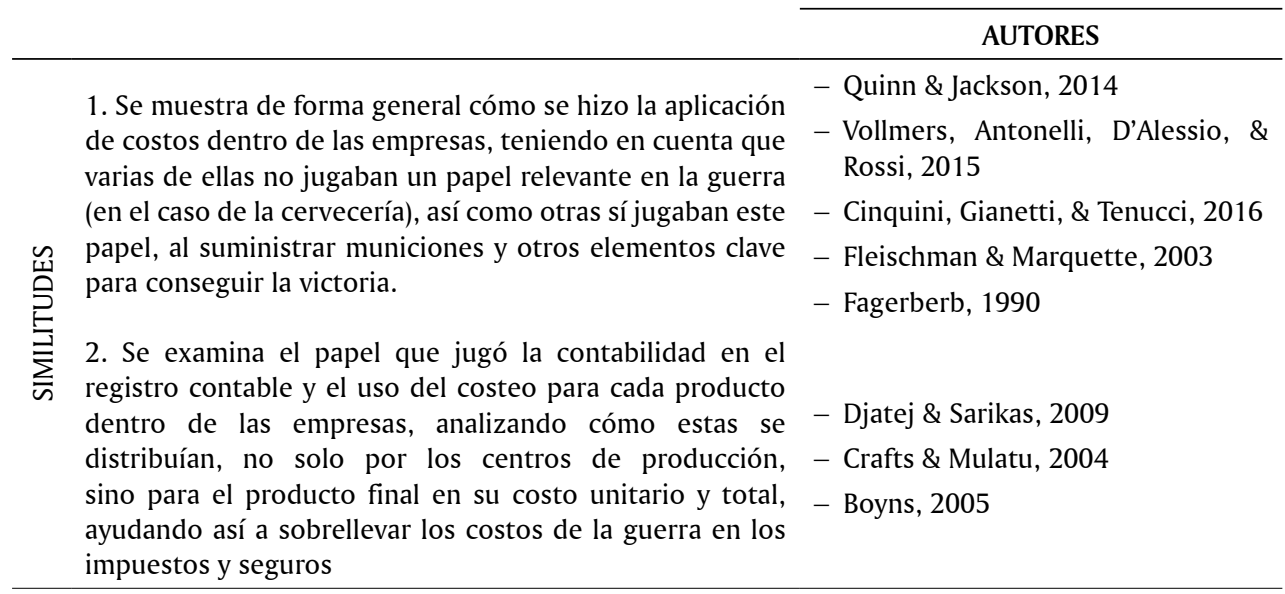

1. En algunos documentos se relataban otros tipos de costos que generalmente no se manejan en una empresa, como el caso de la educación de los niños y la pérdida de capital humano a través de las guerras, los cuales afectan seriamente la productividad de una nación puesto que, sin personas capacitadas para laborar en un área determinada, - Ichino \& Winter-Ebmer, 2004

- Hughes \& Meek, 2014 muchas veces se pueden realizar productos defectuosos o sin los estándares adecuados.

2. Muchas veces, los costos sociales de la guerra no son asumidos por el estado, y, por ende, no son documentados, y aunque incluso estuviesen documentados, muchos de estos registros están perdidos como consecuencia de ocultar evidencia o simplemente la pérdida de los registros. Esto hace que sea más difícil determinar por parte del gobierno (en tiempos posteriores a consecuencia de - Ichino \& Winter-Ebmer, 2004

- Tyson \& Fleischman, 2006

- Hughes \& Meek, 2014 tutelas impuestas o de investigaciones realizadas) el cómo indemnizar a las víctimas, a sus hijos o nietos.

Fuente: Elaboración propia.

Como conclusión, se pudo evidenciar que los costos son uno de los elementos de la contabilidad que más se han trabajado por parte de los autores; y también fue un elemento que repercutió durante las guerras mundiales, al ser un elemento base para las empresas productoras de insumos de guerra y de otros elementos (como en el caso de la cervecería, la cual fabricaba un tipo de cerveza (brew-ale)). Durante la guerra, se fueron aplicando diferentes tipos de costos a los productos, los cuales los asumía la empresa junto a seguros de guerra que el mismo gobierno les hacía aplicar a cada producto en su costo unitario y costo total, para que así la empresa asumiera, en el caso de que existiera, la pérdida del producto por factores bélicos, así como el cambio de 
modelos de costos que cada industria tuvo que adaptar de acuerdo con las necesidades de la época.

\section{IV.II. Historia general de la contabilidad}

En la historia general de la contabilidad, se buscó establecer lo trabajado en la contabilidad de la primera y segunda guerra mundial, bajo ciertos parámetros, como, por ejemplo, el interés por parte de la profesión en cuanto a diversos temas como costos, sector público, etc., y cómo en aras de la situación que se vivía en la época se evidenciaba lo trabajado como un aporte beneficioso para la profesión. Dentro de esta categoría se encuentran los siguientes elementos trabajados dentro de los documentos:

Figura 4: Listado de las diferentes subcategorías halladas en los textos de la categoría de historia general de la contabilidad

\begin{tabular}{|l|}
\hline \multicolumn{1}{|c|}{ Historia General de la Contabilidad } \\
\hline - Interés del sector público en la contabilidad \\
- Interés por la contabilidad en medios escritos \\
- Interés de la contabilidad en la enmancipación femenina \\
- Interés en nuevos modelos contables efectivos para la época \\
- La contabilidad como referente para atender el costo de la violencia y la expansión bélica \\
\hline
\end{tabular}

Fuente: Elaboración propia.

La metodología trabajada en cada uno de los textos en general se presentó como una metodología descriptiva-exploratoria, debido a que se pretendía ver el interés en grupos de personas que estaban familiarizadas con el campo de la contabilidad en el período objeto de estudio. Esto se puede evidenciar en el texto "Field, capital and habitus: An oral history of women in accounting in Australia during World War II", de Ikin, Johns y Hayes (2012) en el que se hace un relato oral sobre mujeres australianas que trabajaron durante la Segunda Guerra Mundial como contadoras.

Durante este tiempo, ellas se enfrentaban a diversos problemas, como los prejuicios que se tenían a la hora de ser contratadas (habiendo una mayor contratación de hombres que de mujeres), las habilidades que tenían ellas en cuanto a las relaciones humanas y la disposición proactiva que se debía tener en aquel entonces: "Las mujeres eran vistas como influidas por sus emociones y, por lo tanto, no se les daba la capacidad de emitir juicios racionales" (Ikin, Johns, \& Hayes, 2012, pág. 177). Fue por este motivo que dentro de los distintos campos de la contabilidad que se manejaban en aquellos tiempos (como lo fueron la auditoría, los impuestos y la emisión de los estados financieros), muchos hombres contratados dentro de firmas contables y de auditoría, la 
Torres, D. Aproximación a la Literatura de la Contabilidad Militar en la Primera y Segunda Guerra Mundial

estigmatización hacia la mujer era un elemento que se veía frecuentemente, aunque luego se demostró que podían hacer el mismo trabajo e incluso de mejor forma que un hombre.

Las similitudes y diferencias entre los textos son los siguientes:

Tabla 2: Similitudes y diferencias de la categoría de la historia general de la contabilidad

1. En el marco de esta investigación, se hacen aportes muy valiosos
en cuanto a la importancia de la contabilidad en el tiempo de
guerra, teniendo en cuenta cómo esta se adaptó debido a las - Gallhofer \& Haslam, 2003
exigencias de la época, ideando nuevos modelos contables, y, - Chwastiak \& Lehman, 2008
sobre todo, abordando lo relativo a la profesión y su desarrollo en
el marco de un paradigma nuevo en el periodo de la guerra
2. Se hacen duras críticas al sistema contable de la época, en el
que había demasiadas falencias, tanto en el modo en el que los - Ikin, Johns, \& Hayes, 2012
registros eran llevados, como en la eficiencia y eficacia de los - Miley \& Read, 2012
sistemas usados, y cómo estos podrían mejorarse.
1. A pesar de que todos coinciden en que los sistemas tenían
falencias evidentes, cada sistema presentado en los textos suele
tener distintos tipos de deficiencias (bien sea por una pobre
aplicación de costos en las empresas, pobres sistemas de control, - Ikin, Johns, \& Hayes, 2012
inadecuado manejo de recursos, etc.) dependiendo del país y
las exigencias del gobierno, los entes fiscales y las empresas
existentes en la época.
2. A pesar de que la profesión contable fue valiosa en el tiempo
de guerra, se cuestiona el compromiso de la profesión contable,
no solo en el sector público, sino en otros sectores, teniendo en
cuenta que, aunque hubo esfuerzos de parte de la profesión en - Walker, 2017
aquella época, muchos gobernantes y empresarios tenían intereses
propios por satisfacer, y en este sentido, el contador tenía que
redefinirse en medio de la tensión entre los dos extremos.

Fuente: Elaboración propia.

Como conclusión, se pudo determinar que existieron muchos grupos de interés en la profesión que determinaron la forma en la que la contabilidad podía ser expresada a través de diferentes procesos, viéndolo como una forma de llevar registros, y también siendo un medio de expansión y apertura a la aceptación general (en el caso de las contadoras australianas) y del impacto obtenido por medios escritos (como la prensa de Red Clydeside) en la guerra, lo cual catapultó la profesión para ser conocida y reconocida como un elemento valioso que permitía, no solo la valuación y el inventario de los activos y pasivos de las empresas, sino como mediante este se podían hacer críticas a los sistemas usados por empresas y por la misma milicia, resaltando sus debilidades en cuanto a la eficiencia y eficacia de las operaciones realizadas por estos. 


\section{IV.III. Historia general de la contabilidad militar}

La historia general de la contabilidad bélica o la contabilidad militar denominada así por Hernández (2015), se trata de una de las tantas vertientes que la nueva historia de la contabilidad ha decidido ahondar para determinar sus efectos en cuanto a la forma en la que se registraban las partidas y se detallaban en los estados financieros de las empresas (independientemente de si se trataban de empresas manufactureras o no) y de cómo tenían impactos y repercusiones en los elementos de la contabilidad. Dentro de esta categoría se encuentran los siguientes ítems:

Figura 5: Listado de las diferentes subcategorías halladas en los textos de la categoría de historia general de la contabilidad militar

\begin{tabular}{|c|}
\hline Historia General de la Contabilidad Militar \\
\hline - Historia General de la contabilidad militar a nivel mundial \\
- La contabilidad como eje importante en los países en guerra \\
- Impactos y consecuencias a nivel contable luego de la guerra \\
\hline
\end{tabular}

Fuente: Elaboración propia.

La metodología trabajada en los textos fue de tipo cualitativa, descriptiva y exploratoria, en parte puesto que se hacían comentarios y se detallaban los diferentes textos que los autores habían trabajado sobre el tema, y también se hacían ciertos énfasis en lo ocurrido en el contexto de la guerra. Un ejemplo es el texto "Accounting for victory" de Funnell y Walker (2014), en el que se critica la contabilidad y muestra cómo la contabilidad, a pesar de estar separada en diferentes elementos, logra ser una sola, incluso en tiempos de crisis y fracaso en el campo de batalla, pero, al mismo tiempo, los costos financieros de la guerra, seguidos por las fallas en la administración de los recursos gracias a ministerios y comités que manejaban los recursos públicos hicieron que los sistemas contables evolucionaran para cada uno de estos, fortaleciéndolos y haciendo que evolucionaran de acuerdo a los requerimientos establecidos.

Las similitudes y diferencias entre los textos son los siguientes: 
Torres, D. Aproximación a la Literatura de la Contabilidad Militar en la Primera y Segunda Guerra Mundial

Tabla 3: Similitudes y diferencias de la categoría de historia general

de la contabilidad militar

\begin{tabular}{|c|c|c|}
\hline & & AUTORES \\
\hline 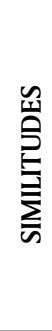 & $\begin{array}{l}\text { En este campo se han mostrado trabajos interesantes sobre la } \\
\text { contabilidad bélica elaborado por diferentes autores a los que el } \\
\text { tema les ha llamado en gran manera la atención, hasta tratar temas } \\
\text { relevantes dentro de este, como problemas persistentes en la } \\
\text { contabilidad como secuelas producto de la guerra, o también mostrar } \\
\text { cómo la contabilidad tuvo un rol importante en los países que estaban } \\
\text { en medio del conflicto, teniendo en cuenta las mediciones de los } \\
\text { recursos y elementos con los que contaban antes, durante y luego de } \\
\text { la guerra. }\end{array}$ & - Hernandez, 2015 \\
\hline 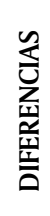 & $\begin{array}{l}\text { Muchos elementos suelen ser confusos, o no llevar una línea de tiempo } \\
\text { concreta, sino que son completamente al azar (como las explicaciones } \\
\text { de Hernández Esteve acerca de los textos que conocía sobre la } \\
\text { contabilidad militar), e incluso, las explicaciones brindadas por los } \\
\text { autores suelen dejar vacíos en cuanto la argumentación del problema } \\
\text { base en los demás textos. }\end{array}$ & $\begin{array}{l}\text { - Giroux, } 2017 \\
\text { - Funnell \& Walker, } 2014\end{array}$ \\
\hline
\end{tabular}

Fuente: Elaboración propia.

Como conclusión, se pudo explorar un poco más acerca del campo contable en los enfrentamientos militares de la Primera y Segunda Guerra Mundial, en el que muchos elementos de la guerra venían siendo elementos básicos en las empresas, e incluso en la milicia, para llevar una buena administración de los recursos que se manejaban en la época. A pesar de que lo narrado por Hernández Esteve sea un referente de todas las investigaciones realizadas por autores en cuanto a la contabilidad bélica (tanto a nivel mundial como en España en diferentes épocas), ha marcado un referente especial en cuanto ha sido el primero en relatar el surgimiento de textos que hablen acerca del tema. En cuanto a los otros dos textos, muestran cómo los elementos de la contabilidad pudieron ayudar a establecer paradigmas y cambios en los sistemas contables y sus impactos y consecuencias.

\section{IV.IV. Tributaria}

En la parte de tributación se investigó la forma de gravar con impuestos, específicamente dos impuestos que las empresas tenían que pagar por órdenes del gobierno británico: el Impuesto a las ganancias excedentes (Excess Profits Duty o EPD) y el Impuesto al entretenimiento (Entertainments Tax o ET), los cuales fueron creados en torno al escenario de la Primera Guerra Mundial como una forma de recaudo adicional para la financiación del conflicto bélico y para terminar con las empresas que se aprovecharon de los estragos de la guerra, junto a los impactos que tuvo en las empresas la aplicación de ambos y el alcance de las revelaciones a los estados financieros hacia los accionistas. 
La metodología trabajada en cada uno de los textos era predominantemente descriptiva, en cuanto se buscaba narrar la forma en la que ambos impuestos se impusieron y la forma en la impactó a las empresas (fuese para bien o para mal), junto al aceleramiento del desarrollo contable de la época. En el texto "Innovation and pragmatism in tax design: Excess Profits Duty in the UK during the First World War" de Billings y Oats (2014), se revela que el EPD fue uno de los primeros intentos que Inglaterra logró hacer para gravar las ganancias excesivas en las empresas, aparte de ser la innovación fiscal en la época de la Primera Guerra Mundial para recaudar fondos, gracias a que se logró investigar a fondo los factores económicos y comerciales existentes y la forma en la que las ganancias se obtenían y distribuían en las empresas, buscando que se generaran más ingresos para apoyar el gasto de guerra y que todas las empresas ayudaran a este fin.

En cuanto al ET, en el texto "The war, taxation and the Blackpool Tower Company" de Rutterford y Walton (2014) se habla que este impuesto comenzó a ser recaudado en 1915, y a pesar de que el EPD tuviera un recaudo mucho más elevado y más poco tiempo de recaudo (siendo su total neto de $£ 1274$ millones, y el tiempo estimado de duración del recaudo fuese de solo siete años), el ET, recaudado hasta 1960 (como forma de paliar los efectos de la Segunda Guerra Mundial y el periodo de ambas postguerras) lograba pequeñas sumas anuales en comparación al EPD (entre $£ 5$ millones y $£ 12$ millones durante la guerra), pero, el ET obtuvo más ingresos debido a todas las empresas que prestaban el servicio de entretenimiento en el país, en especial Blackpool Tower Company.

Las similitudes y diferencias entre los textos son los siguientes:

Tabla 4: Similitudes y diferencias de la categoría de historia general de la categoría tributaria

AUTORES

Se explican dos tipos de impuestos esenciales en aquellas épocas,
los cuales pretendían financiar el gasto de guerra impuesto por el - Billings \& Oats, 2014
gobierno, y en cierto modo, revelar a los accionistas la forma en la - Rutterford \& Walton, 2014
que se pagaba el gasto de guerra mediante estos impuestos.

Fuente: Elaboración propia.

Como conclusión, a pesar de que el gobierno inglés hizo un gran esfuerzo en cuanto a la creación y puesta en marcha de estos impuestos, surgieron 
problemas frente a ambos. En cuanto al EPD, muchos autores estaban de acuerdo con que el rendimiento del impuesto era bastante alto para la época, pero no tanto como debió haber sido (tenía una tasa efectiva del $34 \%$ y no del 63\% que era la tasa legal promedio de la época); así como que también el impuesto tuvo marcadas dificultades en cuanto al tiempo de recaudo y la recolección como tal, por lo cual, muchas empresas (en las que se encontraba Blackpool Tower) tuvieron grandes variaciones en los rendimientos hacia 19141916, y subiendo considerablemente en 1918-1921 debido a pérdidas de años anteriores por efectos del impuesto.

También en cuanto al ET, Blackpool lo consideraba como una afectación mayor que el EPD, al tener efectos significativos en la rentabilidad de los cines y teatros a cargo, y muy a pesar de que en algún momento EPD para la empresa fuese un problema y no se hubiese pagado a lo largo del tiempo en el que estuvo en vigencia, el ET era aplicado de forma independiente a las ganancias, por lo que tuvo un efecto negativo en el entretenimiento ofrecido por la empresa.

\section{IV.V. Estudios de género}

Dentro de los documentos también se analizó lo relativo a los estudios de género. En el documento que escribieron Wooton y Spruill (2014) pretendieron estudiar cómo se dio la entrada de las mujeres a la profesión contable en la Segunda Guerra Mundial, proporcionándoles su primera gran oportunidad para ingresar a la profesión en un terreno en el cual se desalentaba la entrada a la especialización y a la certificación para ser CPA.

La metodología trabajada en este texto fue descriptiva-exploratoria, en el cual se pretendía mostrar la forma en la que las mujeres ingresaron a la contabilidad por suerte, debido a los estigmas que se tenían para la contratación de personal femenino dentro de las firmas contables. Pero debido a los eventos de la Segunda Guerra Mundial, la escasez de hombres requirió que muchas firmas de contabilidad reconsideraran su postura sobre la contratación de mujeres y, en muchos casos, las reclutaran activamente para puestos contables.

Dentro del periodo objeto de estudio, se pudo evidenciar que las mujeres fueron contratadas como "contables" o "bookkeepers", aumentando su número hasta alcanzar (en aras de la Segunda Guerra Mundial) el 51.1 por ciento del personal contable empleado en ese entonces, teniendo un éxito igual al de los hombres. Sin embargo, y debido a los prejuicios que se tenían en aquel entonces debido al fuerte conservadurismo de la época, las mujeres no podían estudiar, convertirse en contadores certificados, o tener un trabajo estable, dejándolas sin oportunidad frente a los hombres, quienes podían obtener mejores posibilidades de empleo, incluso en formas de auditoría. Esto cambia en cuanto se dio el estallido de la guerra, debido a que disminuyó el número de hombres empleados y el de las mujeres aumentó lenta pero gradualmente. 
Como conclusión, la contratación de personal femenino se dio a raíz de la guerra, (y no fue solo para la época de la guerra, sino que ha perdurado hasta la actualidad), debido a que el factor de la guerra, al llevarse a los hombres al campo de batalla, dio posibilidades a las mujeres para desempeñarse laboralmente en un área donde predominaba el género masculino, habiendo un mejor contacto entre hombres y mujeres contables, y que finalmente en los campus universitarios de Estados Unidos se aceptaran mujeres para poder certificarse como CPA, hicieron que en el gigante de América se lograran avances relativos al tema contable.

\section{IV.VI. Estudios de género / Costos}

Esta categoría es de carácter especial, que se decidió añadir, debido a que es interesante el estudio de los costos dentro de los estudios de género y como estos pueden ir de la mano. El texto "War, Women and Accounting: Female Staff in the UK Army Pay Department Offices, 1914 - 1920" de Black (2006) resalta el papel de las mujeres que fueron empleadas oficialmente (aunque de manera temporal) en puestos administrativos y contables en las oficinas del Departamento de Pagos del Ejército (APD) en el Reino Unido de 1914 a 1920.

La metodología trabajada en este texto fue descriptiva-exploratoria, en el que se pretendía explorar el papel de las mujeres que trabajaban temporalmente en las oficinas del Ejército y de pago de comandos del Reino Unido, y también en la Subdivisión de Finanzas de la Oficina de Guerra durante la Primera Guerra Mundial, describiendo el papel de la APD y las oficinas de pago del ejército antes de agosto de 1914, junto a las consecuencias posteriores a la guerra y la expansión burocrática que requirieron el reclutamiento de mujeres, primero de forma voluntaria y luego a título oficial.

Se pudo evidenciar que para 1918, la mayoría de personal empleado eran mujeres que trabajaban de forma temporal. Estas mujeres tenían labores importantes, como la redacción de cartas, preparar decisiones para el departamento de guerra, en trabajos contables para las oficinas de pago del ejército, investigar disputas en relación con los contratos de la Oficina de Guerra, y en la codificación y decodificación de telegramas. Claro que, para la época, no había personas conformes con emplear de mujeres en las oficinas de APD en tiempos de guerra entre 1914 y 1920.

Como conclusión, la organización y la administración del pago de los subsidios en Inglaterra fue un tema notablemente descuidado, aunque la eficiencia del sistema fue una gran contribución a la "relativa" alta moral del ejército de combate. No obstante, la mayoría de los estudios de la Primera Guerra Mundial negaron el papel de la mujer y la guerra debido a que el mismo descontento de diferentes partes hacia ellas como una parte proactiva dentro de las organizaciones no eran de su agrado, incluyendo el descontento general 
que se tuvo al hacer esta contratación, ya que muchas de ellas no tenían experiencia y, por ende, carecían de las habilidades para ejecutar correctamente los procesos dentro de las oficinas.

\section{IV.VII. Pensiones}

Dentro de las pensiones, el único documento que se encontró sobre el tema, fue el denominado "The purgatorial shadows of war: accounting, blame and shell shock pensions" de Frances y Read (2016) pretende determinar la forma en la que se entregaron las pensiones por discapacidad auditiva (en este caso por problemas en la concha acústica, teniendo en cuenta que para la época se clasificaba con nombres de otras patologías que no tenían nada que ver con la discapacidad como tal) en Gran Bretaña.

La metodología trabajada en este texto fue explicativa-exploratoria, en cuanto se pretendía explicar los procedimientos para determinar que una persona sufriera de discapacidad en la concha acústica y por lo tanto recibiera una pensión por supervivencia. Pero, a la hora de otorgar estas pensiones, existían muchos prejuicios desde la contabilidad para la entrega de esta ayuda.

Dentro del periodo objeto de estudio, se pudo evidenciar que, a través del Ministerio de Pensiones, los pagos de estas por este tipo de discapacidad no eran bien recibidas y solamente se contaba con examinar la parte externa del oído, sin tener en cuenta las implicaciones que pudiera tener a nivel interno, y cómo esta podría afectar a la persona en el futuro inmediato, haciendo que no se pagaran lo correspondiente por enfermedad o discapacidad.

Como conclusión, no había una clasificación apropiada (a pesar de que el Ministerio de Pensiones hubiese creado una para poder pagar las pensiones) para el tipo de discapacidad sufrida, incluso aun habiendo cambiado el paradigma desde la profesión médica; aun así, desde la perspectiva del Ministerio, sólo las heridas físicas contaban como medio probatorio para la entrega de las pensiones.

\section{IV.VIII. Contabilidad en el sector público}

En la contabilidad del sector público se notó una gran preocupación acerca de la forma en la que se manejaba; en ese orden de ideas, Cardoni (2014) hizo un estudio basado en dos escuelas de pensamiento francesas, las cuales estaban en auge en la época de la Primera Guerra Mundial, creadas por Paul LeroyBeaulieu y Gaston Jèze, con el supuesto de influir en la gestión de las finanzas públicas del país, además de demostrar el impacto en el financiamiento de la primera guerra mundial por parte del gobierno.

La metodología trabajada en este texto fue descriptiva, la cual trataba de explicar lo que hablaban estas dos escuelas de pensamiento acerca de cómo se debía llevar la contabilidad en el sector público en el tiempo de guerra y los 
impactos que se produjeron a raíz de esto en el financiamiento de la guerra. El texto trata dos partes importantes: los pensamientos preguerra, los cuales eran de carácter liberal para Leroy-Beaulieu (quien se fundamentó en autores como Adam Smith) y de carácter social para Jèze (el cual defendía que no existía un sistema financiero ideal), y el pensamiento en la guerra, en el que teniendo en cuenta a otros autores y posturas (principalmente de países como Alemania, Inglaterra, Italia y Estados Unidos) dieron sus diversos pensamientos acerca de un sistema de políticas para el sector público.

Sin embargo, las ideas y doctrinas políticas que ambas escuelas desarrollaron tuvieron muy poco que ver con la formulación de políticas a lo largo de los años de la guerra, hecho que tuvo bastante que ver con que la escuela de LeroyBeaulieu tomase decisiones deficientes, las cuales hicieron que se provocara inercia económica, seguida de improvisación y retoques financieros que eran más pragmáticos que ideológicos. En cuanto a la escuela de Jèze, se obstaculizó la formulación de políticas porque las ideas de esta impidieron medidas reales de la magnitud de los disturbios que tienen lugar a lo largo de un conflicto bélico, y ninguna de estas ideas fue de ayuda en la economía francesa (la cual era controlada de forma central y cerrada al comercio entre naciones).

Como conclusión, ambas escuelas optaron por políticas pragmáticas, las cuales no ayudaron a establecer un verdadero sistema en el sector público, no se dieron avances en cuanto las finanzas públicas, y mucho menos dar un nuevo sentido al paradigma de este, puesto que "las doctrinas pierden su valor cuando las necesidades financieras son dominantes” (pág. 131). En este sentido, lo propuesto por ambas escuelas no benefició en absoluto a la financiación de la guerra y no tuvo sentido al establecer vaguedades que solo sirvieron como supuestos inservibles.

\section{IV.IV. Presupuestos}

En el tema de presupuestos, Antonelli, D’Alessio y Rossi (2014), los autores realizaron un examen de los presupuestos estatales de Italia en la primera guerra mundial, para así establecer los costos (como las tropas, armas y municiones) en los que se incurrieron durante este tiempo, los cuales fueron administrados por dos ministerios designados: el Ministerio de Guerra (de 1915 a 1917) y luego en conjunto con el Ministerio de Municiones (durante 1917 y 1918), con los que se planeaba mejorar la eficiencia, reducir los costos y prevenir el fraude empresarial y estatal.

La metodología trabajada en este texto es de tipo descriptiva, debido a que narra lo ocurrido en aquella época y muestra la forma en la que se llevaban los presupuestos públicos de parte de ambos ministerios y señalar el efecto de la guerra sobre estas instituciones. También, mostrar que la guerra no condujo a 
la creación de sistemas de control de costos dentro de Italia, y como en otros países se desarrolló de mejor forma.

En el Ministerio de Guerra se adoptaron los procedimientos contables que otros ministerios usaban, y el presupuesto fue elaborado por este en consulta con la Oficina de Contabilidad General y aprobado por el Parlamento. El presupuesto anual de este ministerio se presentó en forma de asignaciones de efectivo para partidas detalladas que se sumaron para las categorías de gastos, haciendo énfasis en la distinción entre gastos ordinarios y extraordinarios. En cuanto al Ministerio de Municiones, se creó en torno a manejar la producción y suministro de materiales de guerra, teniendo un manejo similar al Ministerio de Guerra. Ambos presupuestos proporcionaban otros elementos como la intervención de la Oficina General de Contabilidad y el control ejercido por el Tribunal de Cuentas, aunque, estos procesos no se continuaron durante el período del conflicto, y los presupuestos para los costos de guerra eran vagos.

Como conclusión, dentro de ambos presupuestos, se contemplaban elementos básicos de un presupuesto, hasta que la guerra tuvo lugar, y fue cuando se añadió la partida de gastos de guerra, el cual comprendió casi el $90 \%$ de los costos totales al final del conflicto. Por otro lado, no se realizaban revisiones a los presupuestos por parte de los auditores encargados, por lo que las prácticas presupuestarias en los ministerios italianos se realizaron bajo la presencia de redes económicas y políticas poderosas, ocultando los costos reales de la guerra y, por tanto, ocultaron dudosos acuerdos de contratación en los que se presentaban malversaciones y sobornos. Se pudo evidenciar que no se cumplieron los objetivos de mejorar la eficiencia, reducir los costos y prevenir el fraude empresarial y estatal.

\section{IV.X. Contabilidad de gestión}

En la contabilidad de gestión, el texto "A Brief History of Accounting for Goodwill in Japan and France: War, Tax and Accounting Practice" de García (2011), mostró la contabilidad de los Goodwill en un país oriental y uno occidental (el caso de Japón y Francia), en donde ambos conceptos se manejan de forma distinta, y mostró también que, a pesar de que muchos académicos no estaban de acuerdo con la capitalización del fondo de comercio, las prácticas comerciales cumplían con los requisitos fiscales.

La metodología trabajada en este texto fue descriptiva-exploratoria, explicando la forma en la que este tipo de activos era contabilizado en Japón y Francia, predominando en ambos casos, los impuestos durante el siglo XX. En el caso de Francia, se habían tomado elementos del modelo estadounidense, basado en el consumo y la "agrupación de intereses", en la que no se capitaliza la figura del Goodwill con una amortización contra el patrimonio, mientras 
que los japoneses lo basaban en la fiscalización y, por tanto, para temas relacionados con los impuestos.

Se pudo evidenciar que, en el caso francés, la agrupación de intereses (a diferencia de países como Estados Unidos, Reino Unido, etc.) era más un tratamiento alternativo de la no capitalización del Goodwill con amortización contra el patrimonio, y esta agrupación no se reconocía como costo a las empresas, al igual que los gastos inmediatos o la amortización contra el capital social. En Japón, la amortización contra el patrimonio si era deducible para los fines fiscales correspondientes, por lo tanto, el Goodwill debía ser capitalizado en el balance general.

Como conclusión, la influencia de los impuestos en la historia del Goodwill en ambos países fue relativamente igual. En Francia, la administración tributaria apoyó la retención permanente del Goodwill por razones presupuestarias resultantes de la guerra. Similar a lo que ocurría en Francia, en Japón se adoptó la amortización de la plusvalía en 10 años, pero gravó las ganancias de capital originales como financiamiento de la guerra en la década de 1920. En el periodo de entreguerras, la información financiera creció más allá de la contabilidad fiscal en ambos países.

\section{IV.XI. Responsabilidad social}

En los textos, también se encontraron estudios relativos a la responsabilidad social. El documento "Showing A Strong Front: Corporate Social Reporting And The 'Business Case' In Britain, 1914-1919” de Maltby (2005) buscó mostrar la forma de aplicación de la responsabilidad social corporativa en la Primera Guerra Mundial en Inglaterra, debido a que las compañías británicas se enfrentaron a desafíos graves como cargos de lucro, disturbios industriales y altos impuestos, siendo de especial relevancia estos hallazgos para la presentación de informes sociales contemporáneos.

La metodología trabajada en este texto fue descriptiva, buscando examinar la historia de los informes corporativos en Inglaterra, en cuanto al alcance y la naturaleza de las divulgaciones voluntarias realizadas por compañías limitadas durante la Primera Guerra Mundial y el comienzo del reajuste inmediatamente después de la guerra, teniendo en cuenta la relación entre las compañías limitadas, sus accionistas y la sociedad en general en ese período, y el papel de la información social corporativa.

Se pudo evidenciar que existieron problemas que se abordaron en las reuniones generales de accionistas durante la guerra, e inmediatamente después. Generalmente tenían que ver con la relación entre sociedades limitadas y el gobierno, los empleados, competidores extranjeros, accionistas y otros usuarios. La responsabilidad social se dio principalmente en la industria naviera y en las compañías mineras. Estas compañías, en lugar de alinearse con 
los intereses nacionales, defendían sus propios valores. Esto se logró de forma ambigua: se relataron sus propios logros, y al mismo tiempo se atacó a quienes los criticaron o limitaron su libertad de acción.

Como conclusión, la RSE brindó a las compañías la oportunidad de promover sus negocios hacia las personas interesadas, usando un medio (generalmente prensa escrita) con el que pudiesen comunicar, no solo a los accionistas, sino también a los demás usuarios la información necesaria de acuerdo a sus intereses. Esto hizo que se replanteara el paradigma de la RSE, no como el producto de una nueva ética, sino como una respuesta continua a los desafíos sociales y políticos vividos en esa época, ofreciendo un nuevo margen de estudio para descubrir por qué las empresas lo adoptan y cuáles son los principales temas de discusión para la administración.

\section{IV.XII. Epistemología contable}

También se hallaron documentos relacionados con la epistemología dentro de la contabilidad. En el documento "Cartoons as alternative accounting: front-line supply in the First World War" de Miley y Read (2014), se pretendió mostrar, mediante dibujos, el sistema de contabilidad que apoyaba la provisión de suministros al Frente Occidental durante la Primera Guerra Mundial, el cual tenía serias deficiencias (desde la perspectiva del soldado en la línea del frente). Estas caricaturas fueron hechas por Bruce Bairnsfather, un oficial de primera línea en el ejército británico.

La metodología trabajada en este texto fue descriptiva, relatando lo que los soldados de la línea del frente veían en el sistema contable, el cual para ellos era un sistema con grandes falencias, así como oneroso, desde los requisitos contables hasta la carga de trabajo contable en los oficiales de suministros, haciendo difícil el pensar y proponer alternativas de mejora al sistema contable. Esto se puede ver en los dibujos del soldado Bairnsfather, mediante los cuales buscaba hacer críticas a diferentes elementos deficientes dentro del suministro a los soldados.

Se pudo evidenciar que existieron fallas serias en cada etapa del proceso de suministro, sin embargo, esto sólo se logró evidenciar en la etapa de la entrega de los insumos, lo cual causó que no se apoyara al usuario final como se esperaba. En este sentido, el proceso de suministro mantenía dos sistemas: un sistema en el que se suministraba a los depósitos de las tiendas detrás de las líneas de proa, determinando la naturaleza y el momento de los artículos que ingresan y se mueven a través de este sistema, y otro sistema en que se transferían artículos desde el depósito de las tiendas a los usuarios finales de primera línea (conocido como el sistema "The last mile"); y principalmente se suministraba lo esencial: armas, municiones, alimentos y agua, ropa y elementos 
de higiene personal; no obstante, es relevante mencionar que ninguno de los sistemas estaba documentado.

Como conclusión, esta investigación se sale de lo convencional al considerar que los dibujos e ilustraciones pueden convertirse en contabilidad en sí mismos, proporcionando información complementaria importante que los sistemas contables deben proporcionar, centrándose en apoyar el logro de los objetivos militares equipando a las tropas para un mejor desempeño en el campo de batalla, debido a que sin muchos de estos elementos se puede disminuir la salud (física y mental) y la moral de los soldados, teniendo impactos peligrosos, como la pérdida de vidas y el incumplimiento de los objetivos militares, por lo cual se busca que hayan mejoras en los sistemas contables en el frente de línea, para que sean eficientes y eficaces en cuanto al suministro oportuno, el cumplimiento de requisitos de capacidad y sobre todo, se haga retroalimentación sobre sus deficiencias.

\section{IV.XIII. Auditoría}

Por último, en el tema de la auditoría, Flesher y Previts (2014), hablan acerca de la forma en que la guerra afectó a la empresa de auditoría Haskins \& Sells (conocida actualmente como Deloitte), resaltando factores como la contratación de mujeres para realizar auditorías y prestar servicios, mientras los hombres eran llevados a la guerra por parte del servicio militar estadounidense y las consecuencias que esta situación generó, en relación al progreso de las mujeres contadoras en los servicios de asesoría para lo cual eran solicitadas y finalmente la forma en la que $H \& S$ se convirtió en parte de la comisión de liquidación de la posguerra cuando finalizó la Primera Guerra Mundial.

La metodología trabajada en este texto fue descriptiva, narrando lo ocurrido en la firma de auditoría durante la Primera Guerra Mundial y cómo las mujeres lograron hacer el trabajo contable cuando los hombres eran mandados al campo de batalla, la forma en la que las asesorías brindaban apoyo a las empresas y cómo llegó a ser el liquidador de la posguerra.

Según los autores, la contratación de mujeres en la profesión era un tema polémico, lo cual cambió con la guerra, debido a que el servicio militar estadounidense se llevaba a los hombres a la guerra. Primeramente, se contrataban las mujeres como secretarias (cuando la mayoría eran hombres), y luego se contrataban como Contadoras Certificadas para prestar sus servicios. Este progreso hizo que las mujeres tuvieran cargos importantes como resultado de la guerra, llenando las vacantes creadas por los hombres que se iban al servicio militar. La guerra resultó en mucho más trabajo para los contadores, justamente por la falta de talento humano para realizar ese trabajo.

También, durante este tiempo, las empresas demandaban muchos servicios de asesoría sobre los ingresos, sobre las ganancias excesivas y otras actividades 
para apoyar las operaciones del gobierno. Estas actividades presentaron nuevas oportunidades para los contadores públicos en los Estados Unidos, especialmente tratándose del novedoso sistema de impuesto a la renta individual, el cual era usado para financiar la guerra. En el momento en el que surgió este impuesto, muchas personas no sabían cómo realizar los pagos (o no sabían si al menos debían pagarlos), pedían ayuda a la firma para causarlo ante el gobierno de la época.

Finalmente, en la forma en la que se convirtió en liquidador de la posguerra, lo hizo de varias formas: Primero, haciendo la contabilización de los gastos de la guerra y los asentamientos, vendiendo aquellos activos, suministros y otros materiales que ya no eran necesarios una vez que la guerra terminó, y luego creando una comisión de reparación a las víctimas de la guerra, en la que, de conformidad con el Tratado de Versalles, Alemania debía pagar todos los daños hechos a través de la guerra y reparar a las víctimas.

Como conclusión, a pesar de que la Primera Guerra Mundial se llevara a cabo en Europa, fue un conflicto cuya magnitud se evidenció a nivel global, por lo cual, muchas instituciones de servicios financieros y contadores se involucraron, y Estados Unidos no era la excepción. $H \& S$, siendo la firma de contadores públicos más grande del mundo en ese momento, supo responder a las exigencias de la guerra, haciendo una contratación de mujeres para ayudar cuando se había mermado la cantidad de contadores hombres, en ese orden de ideas su cartera de servicios al cliente creció sustancialmente gracias a la demanda en las asesorías que se daban sobre diversos temas, y a sobrellevar los desafíos que resultaron en la liquidación de la post-guerra, incluyendo la contabilidad de la disposición de los materiales de guerra y la liquidación de reclamaciones.

\section{Conclusiones}

La contabilidad ha sido objeto de múltiples cambios a lo largo del tiempo, desde su auge en la antigua Sumeria hasta el tiempo actual. No obstante, tuvo un impacto bastante significativo en el periodo de guerras, específicamente, en la Primera y Segunda Guerra Mundial. En ese orden de ideas, este momento de la historia sirvió para dar una visión más global a la contabilidad, no solo en cuanto a nuevos procedimientos en registros contables, sino que marcó un referente acerca de ciertos elementos, que en cierta forma no se veían tan necesarios en tiempos anteriores, pero que debido a la rápida evolución de los hechos en un periodo tan abrupto, se hicieron esenciales, tanto para las empresas, ayudando a que se fortalecieran en diversos temas y fueran de ayuda a sus gobiernos mediante la figura de los impuestos, como para que el contador repensara su rol en la sociedad y lo asumiera como un nuevo reto en esos momentos de crisis a nivel mundial. 
En el desarrollo de esta investigación, se pudieron identificar diferentes factores que contribuyeron a mejorar el proceso productivo en las empresas, las tributaciones y los pagos a personal, incluso, a repensar el hecho de que las mujeres son fundamentales para la contabilidad, siendo de gran ayuda en los despachos contables y firmas de auditoría durante el tiempo que los hombres eran enviados a la guerra. Y, desde luego, estos factores tuvieron repercusiones positivas para todos, al convertirse en elementos de ayuda que fueron adaptados por cada organización hasta hacerlas parte integral de ellas, adaptándolos a los nuevos tiempos durante la experiencia del conflicto bélico, y también a los tiempos de cambios que se dieron luego de este.

Tomando en cuenta lo anterior, se pudo ver que, elementos que apenas comenzaban a implementarse, como los costos variables dentro del precio de los productos, o los Goodwill fueron de gran interés, no solo para las empresas y los gobiernos, sino también para la contabilidad en sí como una rama académica (aunque esto se diese tiempo después). Esto se evidencia en el hecho de que las empresas asumieran elementos del costo dentro de la producción terminada, especialmente en el precio unitario de los productos terminados; o la creación de nuevos elementos de financiación para el periodo de guerras, como nuevos impuestos, todo con la finalidad de dar soporte al gobierno y a los batallones militares en el desarrollo de la guerra, y así mismo financiar los gastos que representaba el conflicto bélico. Esto trajo beneficios e hizo que, luego de su implementación, tuvieran mejoras, no solo en los procesos productivos, sino también en el alivio del gasto que generaba la guerra.

También, se pudo evidenciar algunas similitudes y diferencias entre los estudios, a pesar de solo tener algunas categorías con varios textos dentro de un mismo conjunto, lo cual ayuda a esclarecer un poco lo que se investigó por parte de los autores; siendo esto un indicador positivo de que muchos de los elementos anteriormente expuestos reflejan el comportamiento contable dentro de las entidades gubernamentales y las empresas y cómo fueron adaptados y usados a pesar de lo duro que fue la época para ellos y para los avances en materia de la contabilidad.

Finalmente, este trabajo de investigación ayudó a esclarecer un derrotero en los estudios acerca de la relación entre el conflicto bélico y la contabilidad, puesto que anteriormente los autores, estudiosos de los fenómenos contables no estaban interesados en un principio en explorar este ámbito, sin embargo y con las transformaciones contables que surgieron a lo largo de las épocas de guerras (según lo relatado por Hernández Esteve) se comenzaron a dar avances de cómo se llevaba la contabilidad en medio de lo bélico, y cómo este fue un periodo coyuntural con el surgimiento de nuevos procesos e impuestos que ayudaran a las empresas a hacer su trabajo en medio de las dificultades que acarreaba un proceso bélico de grandes magnitudes. 
Torres, D. Aproximación a la Literatura de la Contabilidad Militar en la Primera y Segunda Guerra Mundial

\section{VI.Apéndice}

Apéndice 1: Estructura PICOT y Tesauro para validación de términos

Tabla 5: Estructura PICOT

Tabla 6: Tesauros para validación de términos en inglés

Apéndice 2: Matriz primaria

Apéndice 1: Estructura PICOT y Tesauro para validación de términos

Tabla 5: Estructura PICOT

\begin{tabular}{cl}
$\begin{array}{c}\text { ESTRUCTURA } \\
\text { PICOT }\end{array}$ & COMPONENTES \\
\hline $\mathrm{P}$ & $\begin{array}{l}\text { La población por abordar será la población masculina y femenina involucrada en temas } \\
\text { contables en las dos guerras mundiales, así como en el periodo de entreguerras. }\end{array}$ \\
\hline $\mathrm{I}$ & $\begin{array}{l}\text { La primera categoría está asociada a establecer los principales temas de desarrollo de la } \\
\text { contabilidad como saber disciplinar durante el periodo objeto de estudio. }\end{array}$ \\
\hline $\mathrm{C}$ & $\begin{array}{l}\text { La segunda categoría es establecer diferencias y similitudes entre los temas encontrados } \\
\text { en la revisión documental. }\end{array}$ \\
\hline $\mathrm{O}$ & $\begin{array}{l}\text { En cuanto a los resultados, se espera identificar cuáles son los temas trabajados por los } \\
\text { autores en cuanto a la contabilidad militar en las guerras mundiales. }\end{array}$ \\
\hline $\mathrm{T}$ & El periodo a abordar será desde el año 1990 hasta el año 2019. \\
\hline
\end{tabular}

Fuente: Elaboración propia.

Selección de Palabras clave: Para la selección de las palabras clave, se realizó la extracción de estas desde la estructura PICOT, y fueron traducidas al idioma inglés por ser el más usado en las bases de datos a nivel mundial.

P: Hombres, Mujeres, Contabilidad.

I: Saber Disciplinar, Temas de desarrollo.

C: Diferencias, Similitudes.

O: Primera Guerra Mundial, Segunda Guerra Mundial, Contabilidad militar.

T: Periodo de tiempo a abordar.

Cada término fue sujeto de evaluación y validación en 4 tesauros: UNESCO Thesaurus; Thesaurus, STW Thesaurus for Economics y Thinkmap Visual Thesaurus. Los resultados se muestran en la siguiente tabla: 
Tabla 6: Tesauros para validación de términos en inglés

\begin{tabular}{|c|c|c|c|c|c|c|}
\hline $\mathbf{N}^{\circ}$ & $\begin{array}{r}\text { TÉRMINO } \\
\text { ESPAÑOL } \\
\end{array}$ & $\begin{array}{l}\text { ENGLISH } \\
\text { TERM }\end{array}$ & $\begin{array}{l}\text { ACADEMIC SEARCH } \\
\text { COMPLETE }\end{array}$ & $\begin{array}{l}\text { THESAURUS } \\
\text { (Synonyms) } \\
\end{array}$ & $\begin{array}{l}\text { STW THESAURUS } \\
\text { FOR ECONOMICS }\end{array}$ & $\begin{array}{c}\text { THINKMAP VISUAL } \\
\text { THESAURUS } \\
\end{array}$ \\
\hline 1 & Contabilidad & Accounting & $\begin{array}{l}\text { Financial } \\
\text { Statements, } \\
\text { Finance, Banking, } \\
\text { Accountants, } \\
\text { Auditing }\end{array}$ & $\begin{array}{l}\text { Bookkeeping, } \\
\text { computing, } \\
\text { auditing, } \\
\text { calculating, }\end{array}$ & $\begin{array}{l}\text { Accounting } \\
\text { theory, corporate } \\
\text { tax management }\end{array}$ & $\begin{array}{l}\text { Accountancy, } \\
\text { method of } \\
\text { accounting, } \\
\text { accounting } \\
\text { system, account } \\
\text { statement, }\end{array}$ \\
\hline 2 & $\begin{array}{l}\text { Hombres / } \\
\text { Contabilidad }\end{array}$ & $\begin{array}{l}\text { Men / } \\
\text { Accounting }\end{array}$ & No results & No results & No results & No results \\
\hline 3 & $\begin{array}{l}\text { Mujeres / } \\
\text { Contabilidad }\end{array}$ & $\begin{array}{l}\text { Women / } \\
\text { Accounting }\end{array}$ & No results & No results & No results & No results \\
\hline 4 & $\begin{array}{l}\text { Saber } \\
\text { disciplinar }\end{array}$ & $\begin{array}{l}\text { Disciplinary } \\
\text { knowledge }\end{array}$ & $\begin{array}{l}\text { Education, } \\
\text { Learning, } \\
\text { Interdisciplinary } \\
\text { research }\end{array}$ & No results & No results & No results \\
\hline 5 & $\begin{array}{l}\text { Temas de } \\
\text { desarrollo }\end{array}$ & $\begin{array}{l}\text { Development } \\
\text { issues }\end{array}$ & $\begin{array}{l}\text { Economic } \\
\text { development, } \\
\text { education, } \\
\text { globalization }\end{array}$ & No results & No results & $\begin{array}{l}\text { Developmental, } \\
\text { issues }\end{array}$ \\
\hline 6 & $\begin{array}{l}\text { Diferencias / } \\
\text { Contabilidad }\end{array}$ & $\begin{array}{l}\text { Differences / } \\
\text { Accounting }\end{array}$ & No results & No results & No results & No results \\
\hline 7 & $\begin{array}{l}\text { Similitudes / } \\
\text { Contabilidad }\end{array}$ & $\begin{array}{l}\text { Similarities / } \\
\text { Accounting }\end{array}$ & No results & No results & No results & No results \\
\hline 8 & $\begin{array}{l}\text { Primera } \\
\text { Guerra } \\
\text { Mundial }\end{array}$ & $\begin{array}{l}\text { First World } \\
\text { War / WWI }\end{array}$ & $\begin{array}{l}\text { War, military } \\
\text { history, War and } \\
\text { society, Women } \\
\& \text { war }\end{array}$ & No results & No results & $\begin{array}{l}\text { Great war, World } \\
\text { war I, War to End } \\
\text { War }\end{array}$ \\
\hline 9 & $\begin{array}{l}\text { Segunda } \\
\text { Guerra } \\
\text { Mundial }\end{array}$ & $\begin{array}{l}\text { Second } \\
\text { World War / } \\
\text { WWII }\end{array}$ & $\begin{array}{l}\text { War, military } \\
\text { history, world } \\
\text { war ii }\end{array}$ & No results & No results & World war 2 \\
\hline & $\begin{array}{l}\text { Contabilidad } \\
\text { Militar }\end{array}$ & $\begin{array}{l}\text { Military } \\
\text { Accounting }\end{array}$ & $\begin{array}{l}\text { Accounting, war, } \\
\text { cost of war }\end{array}$ & No results & No results & No results \\
\hline
\end{tabular}

Fuente: Elaboración propia. 
Torres, D. Aproximación a la Literatura de la Contabilidad Militar en la Primera y Segunda Guerra Mundial

Apéndice 2: Matriz primaria

\begin{tabular}{|c|c|c|c|c|c|c|}
\hline $\mathbf{N}^{\circ}$ & Título & Autores & $\begin{array}{c}\text { Año } \\
\text { Publicación }\end{array}$ & Lugar & Categoría & Breve descripción \\
\hline 1 & $\begin{array}{l}\text { Aproximación } \\
\text { al estudio del } \\
\text { pensamiento } \\
\text { Contable, Capítulo } 20 \\
\text { "Contabilidad Militar" }\end{array}$ & $\begin{array}{l}\text { Hernández } \\
\text { Esteve, } \\
\text { Esteban }\end{array}$ & 2015 & $\begin{array}{l}\text { España - } \\
\text { Mundial }\end{array}$ & $\begin{array}{l}\text { Historia } \\
\text { general de la } \\
\text { Contabilidad } \\
\text { militar }\end{array}$ & $\begin{array}{l}\text { Historia general de la } \\
\text { Contabilidad militar y } \\
\text { aproximación a escritos } \\
\text { de este campo. }\end{array}$ \\
\hline 2 & $\begin{array}{l}\text { Accounting History } \\
\text { and the Rise } \\
\text { of Civilization, } \\
\text { Volume II, Chapter } \\
5 \text { "Post World War } \\
\text { II Bussiness and } \\
\text { Accounting" }\end{array}$ & $\begin{array}{l}\text { Giroux, } \\
\text { Gary }\end{array}$ & 2017 & Mundial & $\begin{array}{l}\text { Historia } \\
\text { general de la } \\
\text { Contabilidad } \\
\text { militar }\end{array}$ & $\begin{array}{l}\text { Problemas que } \\
\text { quedaron luego de } \\
\text { la guerra en cuanto a } \\
\text { temas contables. }\end{array}$ \\
\hline 3 & $\begin{array}{l}\text { The purgatorial } \\
\text { shadows of war: } \\
\text { accounting, blame } \\
\text { and shell shock } \\
\text { pensions }\end{array}$ & $\begin{array}{l}\text { Miley, } \\
\text { Frances; } \\
\text { Read, } \\
\text { Andrew }\end{array}$ & 2016 & $\begin{array}{l}\text { Reino } \\
\text { Unido }\end{array}$ & Pensiones & $\begin{array}{l}\text { Determinación de } \\
\text { pago de pensiones } \\
\text { a personas con } \\
\text { problemas de concha } \\
\text { acústica. }\end{array}$ \\
\hline 4 & $\begin{array}{l}\text { Cost Accounting for } \\
\text { War: Contracting } \\
\text { Procedures and } \\
\text { Cost-plus Pricing } \\
\text { in WWI Industrial } \\
\text { Mobilization in Italy }\end{array}$ & $\begin{array}{l}\text { Vollmers, } \\
\text { Gloria; } \\
\text { Antonelli, } \\
\text { Valerio; } \\
\text { D’Alessio, } \\
\text { Raffaele; } \\
\text { Rossi, } \\
\text { Roberto }\end{array}$ & 2015 & Italia & Costos & $\begin{array}{l}\text { Procedimientos de } \\
\text { aplicación de costos en } \\
\text { la fábrica Ansaldo. }\end{array}$ \\
\hline 5 & $\begin{array}{l}\text { Accounting for } \\
\text { Victory }\end{array}$ & $\begin{array}{l}\text { Funnell, } \\
\text { Warwick; } \\
\text { Walker, } \\
\text { Stephen P. }\end{array}$ & 2014 & Mundial & $\begin{array}{l}\text { Historia } \\
\text { general de la } \\
\text { Contabilidad } \\
\text { militar }\end{array}$ & $\begin{array}{l}\text { Explicación de la } \\
\text { contabilidad siendo } \\
\text { importante para los } \\
\text { países en guerra. }\end{array}$ \\
\hline 6 & $\begin{array}{l}\text { Accounting for } \\
\text { war risk costs: } \\
\text { management } \\
\text { accounting change at } \\
\text { Guinness during the } \\
\text { First World War }\end{array}$ & $\begin{array}{l}\text { Quinn, } \\
\text { Martin; } \\
\text { Jackson, } \\
\text { William J. }\end{array}$ & 2014 & Irlanda & Costos & $\begin{array}{l}\text { Cambios en los } \\
\text { procedimientos } \\
\text { contables (costos) y } \\
\text { aplicación de nuevas } \\
\text { prácticas debido } \\
\text { a los riesgos de la } \\
\text { guerra que influyeron } \\
\text { notablemente en la } \\
\text { cervecería. }\end{array}$ \\
\hline
\end{tabular}




\begin{tabular}{|c|c|c|c|c|c|c|}
\hline $\mathbf{N}^{\circ}$ & Título & Autores & $\begin{array}{c}\text { Año } \\
\text { Publicación }\end{array}$ & Lugar & Categoría & Breve descripción \\
\hline 7 & $\begin{array}{l}\text { The 'science' of } \\
\text { French public } \\
\text { finances in the First } \\
\text { World War }\end{array}$ & $\begin{array}{l}\text { Cardoni, } \\
\text { Fabien }\end{array}$ & 2014 & Francia & $\begin{array}{l}\text { Contabilidad en } \\
\text { Sector Público }\end{array}$ & $\begin{array}{l}\text { Estudio sobre los } \\
\text { pensamientos de dos } \\
\text { personajes en cuanto } \\
\text { a las finanzas públicas } \\
\text { en francia y su impacto } \\
\text { en la financiación } \\
\text { de la primera guerra } \\
\text { mundial. }\end{array}$ \\
\hline
\end{tabular}

\section{Haskins \& Sells} during the First World War and its aftermath
Flesher,

Dale L.;

Previts,

Gary J.

\section{4}

Estados Auditoría

Unidos

Unidos

\section{Afectación de empresa de auditoría (Haskins \& Sells (ahora Deloitte)) por la Primera guerra mundial y la forma en la que la demanda con el impuesto sobre la renta, la forma en la que se convirtió en parte de la comisión de liquidación de la post- guerra y la contratación de mujeres cuando los hombres eran llevados a la guerra por parte del servicio militar estadounidense.}

\begin{tabular}{|c|c|c|c|c|c|}
\hline $\begin{array}{l}\text { Innovation and } \\
\text { pragmatism in tax } \\
\text { design: Excess Profits } \\
\text { Duty in the UK during } \\
\text { the First World War }\end{array}$ & $\begin{array}{l}\text { Billings, } \\
\text { Mark; Oats, } \\
\text { Lynne }\end{array}$ & 2014 & $\begin{array}{l}\text { Reino } \\
\text { Unido }\end{array}$ & Tributaria & $\begin{array}{l}\text { Gravación de las } \\
\text { ganancias comerciales } \\
\text { mediante el Excess } \\
\text { Profits Duty (EPD) } \\
\text { como medio para } \\
\text { financiar el gasto } \\
\text { público de la guerra y } \\
\text { frenar la especulación. }\end{array}$ \\
\hline
\end{tabular}


Torres, D. Aproximación a la Literatura de la Contabilidad Militar en la Primera y Segunda Guerra Mundial

\begin{tabular}{|c|c|c|c|c|c|c|}
\hline $\mathbf{N}^{\circ}$ & Título & Autores & $\begin{array}{c}\text { Año } \\
\text { Publicación }\end{array}$ & Lugar & Categoría & Breve descripción \\
\hline 10 & $\begin{array}{l}\text { The war, taxation and } \\
\text { the Blackpool Tower } \\
\text { Company }\end{array}$ & $\begin{array}{l}\text { Rutterford, } \\
\text { Janette; } \\
\text { Walton, } \\
\text { Peter }\end{array}$ & 2014 & $\begin{array}{l}\text { Reino } \\
\text { Unido }\end{array}$ & Tributaria & $\begin{array}{l}\text { Análisis sobre el } \\
\text { impacto del Excess } \\
\text { Profits Duty (EPD) } \\
\text { y el Impuesto al } \\
\text { Entretenimiento } \\
\text { (ET) de la empresa } \\
\text { Blackpool Tower } \\
\text { durante el tiempo de la } \\
\text { guerra, junto al alcance } \\
\text { de las revelaciones } \\
\text { a los accionistas y } \\
\text { las inversiones en } \\
\text { los War Loan debido } \\
\text { al aumento de sus } \\
\text { ganancias. }\end{array}$ \\
\hline 11 & $\begin{array}{l}\text { Budgetary practices } \\
\text { in the Ministry of } \\
\text { War and the Ministry } \\
\text { of Munitions in Italy, } \\
\text { 1915-1918 }\end{array}$ & $\begin{array}{l}\text { Antonelli, } \\
\text { Valerio; } \\
\text { D'Alessio, } \\
\text { Raffaele; } \\
\text { Rossi, } \\
\text { Roberto }\end{array}$ & 2014 & Italia & Presupuestos & $\begin{array}{l}\text { Examinación de } \\
\text { los presupuestos } \\
\text { estatales para los } \\
\text { costos incurridos en } \\
\text { la Primera Guerra } \\
\text { Mundial, administradas } \\
\text { por dos ministerios } \\
\text { (el de Guerra y el } \\
\text { de Municiones), con } \\
\text { los que se planeaba } \\
\text { mejorar la eficiencia, } \\
\text { reducir los costos y } \\
\text { prevenir el fraude. }\end{array}$ \\
\hline 12 & $\begin{array}{l}\text { Cartoons as } \\
\text { alternative } \\
\text { accounting: front-line } \\
\text { supply in the First } \\
\text { World War }\end{array}$ & $\begin{array}{l}\text { Miley, } \\
\text { Frances; } \\
\text { Read, } \\
\text { Andrew }\end{array}$ & 2014 & $\begin{array}{l}\text { Reino } \\
\text { Unido }\end{array}$ & $\begin{array}{l}\text { Epistemología } \\
\text { contable }\end{array}$ & $\begin{array}{l}\text { Muestra mediante } \\
\text { dibujos el sistema } \\
\text { de contabilidad que } \\
\text { apoyaba la provisión de } \\
\text { suministros al Frente } \\
\text { Occidental durante } \\
\text { la Primera Guerra } \\
\text { Mundial, el cual tenía } \\
\text { deficiencias (desde la } \\
\text { perspectiva del soldado } \\
\text { en la línea del frente). }\end{array}$ \\
\hline
\end{tabular}




\begin{tabular}{|c|c|c|c|c|c|c|}
\hline $\mathbf{N}^{\circ}$ & Título & Autores & $\begin{array}{c}\text { Año } \\
\text { Publicación }\end{array}$ & Lugar & Categoría & Breve descripción \\
\hline 13 & $\begin{array}{l}\text { The role of women } \\
\text { in Major Public } \\
\text { Accounting Firms } \\
\text { in the United States } \\
\text { during World War II }\end{array}$ & $\begin{array}{l}\text { Wooton, } \\
\text { Charles; } \\
\text { Spruill, } \\
\text { Wanda }\end{array}$ & 2014 & $\begin{array}{l}\text { Estados } \\
\text { Unidos }\end{array}$ & $\begin{array}{l}\text { Estudios de } \\
\text { género }\end{array}$ & $\begin{array}{l}\text { Entrada de mujeres a } \\
\text { la profesión contable } \\
\text { en la segunda } \\
\text { guerra mundial, } \\
\text { proporcionándoles } \\
\text { su primera gran } \\
\text { oportunidad para } \\
\text { ingresar a la profesión. }\end{array}$ \\
\hline 14 & $\begin{array}{l}\text { Showing A Strong } \\
\text { Front: Corporate } \\
\text { Social Reporting And } \\
\text { The 'Business Case' In } \\
\text { Britain, 1914-1919 }\end{array}$ & $\begin{array}{l}\text { Maltby, } \\
\text { Joseph }\end{array}$ & 2005 & $\begin{array}{l}\text { Reino } \\
\text { Unido }\end{array}$ & $\begin{array}{l}\text { Responsabilidad } \\
\text { Social }\end{array}$ & $\begin{array}{l}\text { Aplicación de la } \\
\text { responsabilidad social } \\
\text { corporativa en el caso } \\
\text { británico de la primera } \\
\text { guerra mundial, debido } \\
\text { a que las empresas } \\
\text { estuvieron expuestas } \\
\text { a cargos de lucro y a } \\
\text { altos impuestos. }\end{array}$ \\
\hline 15 & $\begin{array}{l}\text { Accountants and } \\
\text { the pursuit of the } \\
\text { national interest: A } \\
\text { study of role conflict } \\
\text { during the First } \\
\text { World War }\end{array}$ & $\begin{array}{l}\text { Walker, } \\
\text { Stephen }\end{array}$ & 2017 & $\begin{array}{l}\text { Reino } \\
\text { Unido }\end{array}$ & $\begin{array}{l}\text { Historia } \\
\text { general de la } \\
\text { Contabilidad }\end{array}$ & $\begin{array}{l}\text { Cuestionamiento del } \\
\text { compromiso de la } \\
\text { profesión contable con } \\
\text { el interés público. }\end{array}$ \\
\hline 16 & $\begin{array}{l}\text { Mobilising accounting } \\
\text { in the radical media } \\
\text { during the First } \\
\text { World War and } \\
\text { its aftermath: The } \\
\text { case of Forward in } \\
\text { the context of Red } \\
\text { Clydesid }\end{array}$ & $\begin{array}{l}\text { Gallhofer, } \\
\text { Sonja; } \\
\text { Haslam, Jim }\end{array}$ & 2003 & $\begin{array}{l}\text { Reino } \\
\text { Unido }\end{array}$ & $\begin{array}{l}\text { Historia } \\
\text { general de la } \\
\text { Contabilidad }\end{array}$ & $\begin{array}{l}\text { Análisis histórico } \\
\text { crítico de la } \\
\text { movilización de la } \\
\text { contabilidad en los } \\
\text { medios radicales } \\
\text { en el contexto de } \\
\text { crisis de la Primera } \\
\text { Guerra Mundial y sus } \\
\text { secuelas en Forward, } \\
\text { un importante } \\
\text { semanario radical del } \\
\text { contexto clave del "Red } \\
\text { Clydeside". }\end{array}$ \\
\hline 17 & $\begin{array}{l}\text { A Brief History of } \\
\text { Accounting for } \\
\text { Goodwill in Japan and } \\
\text { France: War, Tax and } \\
\text { Accounting Practice }\end{array}$ & $\begin{array}{l}\text { García, } \\
\text { Cleménce }\end{array}$ & 2011 & $\begin{array}{l}\text { Japón - } \\
\text { Francia }\end{array}$ & $\begin{array}{l}\text { Contabilidad de } \\
\text { Gestión }\end{array}$ & $\begin{array}{l}\text { Busca la contabilidad } \\
\text { de los Goodwill en } \\
\text { países occidentales } \\
\text { (como Japón y Francia), } \\
\text { en donde ambos } \\
\text { conceptos se manejan } \\
\text { de forma distinta }\end{array}$ \\
\hline
\end{tabular}


Torres, D. Aproximación a la Literatura de la Contabilidad Militar en la Primera y Segunda Guerra Mundial

\begin{tabular}{|c|c|c|c|c|c|c|}
\hline $\mathbf{N}^{\circ}$ & Título & Autores & $\begin{array}{c}\text { Año } \\
\text { Publicación }\end{array}$ & Lugar & Categoría & Breve descripción \\
\hline 18 & $\begin{array}{l}\text { Field, capital and } \\
\text { habitus: An oral } \\
\text { history of women } \\
\text { in accounting in } \\
\text { Australia during } \\
\text { World War II }\end{array}$ & $\begin{array}{l}\text { Ikin, } \\
\text { Catherine; } \\
\text { Johns, } \\
\text { Leanne; } \\
\text { Hayes, } \\
\text { Colleen }\end{array}$ & 2012 & Australia & $\begin{array}{l}\text { Historia } \\
\text { general de la } \\
\text { Contabilidad }\end{array}$ & $\begin{array}{l}\text { Se proporciona una } \\
\text { historia oral de mujeres } \\
\text { que trabajaron como } \\
\text { contadoras en Australia } \\
\text { durante la Segunda } \\
\text { Guerra Mundial. En } \\
\text { este, se identifica la } \\
\text { profesión contable } \\
\text { como un campo } \\
\text { jerárquico, donde las } \\
\text { posiciones relativas se } \\
\text { definen en términos de } \\
\text { capital cultural, social y } \\
\text { simbólico asociado. }\end{array}$ \\
\hline 19 & $\begin{array}{l}\text { The implications of } \\
\text { supply accounting } \\
\text { deficiencies in the } \\
\text { Australian Army } \\
\text { during the Second } \\
\text { World War }\end{array}$ & $\begin{array}{l}\text { Miley, } \\
\text { Frances; } \\
\text { Read, } \\
\text { Andrew }\end{array}$ & 2012 & Australia & $\begin{array}{l}\text { Historia } \\
\text { general de la } \\
\text { Contabilidad }\end{array}$ & $\begin{array}{l}\text { Resalta la importancia } \\
\text { crítica de un sistema } \\
\text { de contabilidad militar } \\
\text { orientado a mejorar la } \\
\text { eficiencia y la eficacia } \\
\text { de la guerra debido a } \\
\text { deficiencias prácticas } \\
\text { de los procedimientos } \\
\text { de contabilidad } \\
\text { de suministros del } \\
\text { ejército. }\end{array}$ \\
\hline 20 & $\begin{array}{l}\text { The making of } \\
\text { uniform costing in a } \\
\text { war economy: The } \\
\text { case of the Uniconti } \\
\text { Commission in Fascist } \\
\text { Italy }\end{array}$ & $\begin{array}{l}\text { Cinquini, } \\
\text { Lino; } \\
\text { Gianetti, } \\
\text { Riccardo; } \\
\text { Tenucci, } \\
\text { Andrea }\end{array}$ & 2016 & Italia & Costos & $\begin{array}{l}\text { Establecimiento de } \\
\text { reglas de costeo } \\
\text { uniforme en italia }\end{array}$ \\
\hline 21 & $\begin{array}{l}\text { The Second World } \\
\text { War and Soviet } \\
\text { accounting }\end{array}$ & $\begin{array}{l}\text { Djatej, } \\
\text { Arsen; } \\
\text { Sarikas, } \\
\text { Robert }\end{array}$ & 2009 & $\begin{array}{c}\text { Rusia } \\
\text { (Unión } \\
\text { Soviética) }\end{array}$ & Costos & $\begin{array}{l}\text { Examinación de los } \\
\text { rápidos cambios en } \\
\text { la práctica contable } \\
\text { soviética durante } \\
\text { la Segunda Guerra } \\
\text { Mundial y adaptación } \\
\text { del sistema de } \\
\text { contabilidad anterior a } \\
\text { la guerra para cumplir } \\
\text { con las demandas } \\
\text { extraordinarias de la } \\
\text { guerra y contribuir a la } \\
\text { victoria. }\end{array}$ \\
\hline
\end{tabular}




\begin{tabular}{|c|c|c|c|c|c|c|}
\hline $\mathbf{N}^{\circ}$ & Título & Autores & $\begin{array}{c}\text { Año } \\
\text { Publicación }\end{array}$ & Lugar & Categoría & Breve descripción \\
\hline 22 & $\begin{array}{l}\text { The Impact of World } \\
\text { War II On Cost } \\
\text { Accounting At The } \\
\text { Sperry Corporation }\end{array}$ & $\begin{array}{l}\text { Fleischman, } \\
\text { Richard; } \\
\text { Marquette, } \\
\text { Penny }\end{array}$ & 2003 & $\begin{array}{l}\text { Estados } \\
\text { Unidos }\end{array}$ & Costos & $\begin{array}{l}\text { Muestra la doble cara } \\
\text { de la contabilidad de } \\
\text { costos en los Estados } \\
\text { Unidos. }\end{array}$ \\
\hline 23 & $\begin{array}{l}\text { How did the Location } \\
\text { of Industry Respond } \\
\text { To Falling Transport } \\
\text { Costs in Britain } \\
\text { Before World War I? }\end{array}$ & $\begin{array}{l}\text { Crafts, } \\
\text { Nicholas; } \\
\text { Mulatu, } \\
\text { Abay }\end{array}$ & 2004 & $\begin{array}{l}\text { Reino } \\
\text { Unido }\end{array}$ & Costos & $\begin{array}{l}\text { Este documento } \\
\text { explora la ubicación } \\
\text { de la industria en la } \\
\text { Gran Bretaña anterior } \\
\text { a la Primera Guerra } \\
\text { Mundial utilizando } \\
\text { un modelo que tiene } \\
\text { en cuenta tanto la } \\
\text { dotación de factores } \\
\text { como las nuevas } \\
\text { influencias de la } \\
\text { geografía económica, } \\
\text { y en el que los costos } \\
\text { de transporte tuvieron } \\
\text { un efecto relativamente } \\
\text { pequeño en la } \\
\text { ubicación industrial. }\end{array}$ \\
\hline 24 & $\begin{array}{l}\text { The Long-Run } \\
\text { Educational Cost of } \\
\text { World War II }\end{array}$ & $\begin{array}{l}\text { Ichino, } \\
\text { Andrea; } \\
\text { Winter- } \\
\text { Ebmer, } \\
\text { Rudolf }\end{array}$ & 2004 & $\begin{array}{l}\text { Austria - } \\
\text { Alemania } \\
\text { - Suecia } \\
\text { - Suiza }\end{array}$ & Costos & $\begin{array}{l}\text { Un componente } \\
\text { importante del costo } \\
\text { a largo plazo de una } \\
\text { guerra es la pérdida } \\
\text { de capital humano } \\
\text { que sufren los niños } \\
\text { en edad escolar } \\
\text { que reciben menos } \\
\text { educación. }\end{array}$ \\
\hline 25 & $\begin{array}{l}\text { Accounting for } \\
\text { interned Japanese- } \\
\text { American civilians } \\
\text { during World War II: } \\
\text { Creating incentives } \\
\text { and establishing } \\
\text { controls for captive } \\
\text { workers }\end{array}$ & $\begin{array}{l}\text { Tyson, } \\
\text { Thomas; } \\
\text { Fleischman, } \\
\text { Richard }\end{array}$ & 2006 & $\begin{array}{l}\text { Estados } \\
\text { Unidos }\end{array}$ & Costos & $\begin{array}{l}\text { Administración } \\
\text { de campamentos } \\
\text { para personas de } \\
\text { ascendencia japonesa } \\
\text { en Estados Unidos, } \\
\text { describiendo el uso } \\
\text { que hace la WRA de la } \\
\text { información contable } \\
\text { y sitúa el papel de la } \\
\text { contabilidad dentro de } \\
\text { un marco de proceso } \\
\text { laboral. }\end{array}$ \\
\hline
\end{tabular}


Torres, D. Aproximación a la Literatura de la Contabilidad Militar en la Primera y Segunda Guerra Mundial

\begin{tabular}{|c|c|c|c|c|c|c|}
\hline $\mathbf{N}^{\circ}$ & Título & Autores & $\begin{array}{c}\text { Año } \\
\text { Publicación }\end{array}$ & Lugar & Categoría & Breve descripción \\
\hline 26 & $\begin{array}{l}\text { State Regulation, } \\
\text { Family Breakdown, } \\
\text { and Lone } \\
\text { Motherhood: The } \\
\text { Hidden Costs of } \\
\text { World War I in } \\
\text { Scotland }\end{array}$ & $\begin{array}{l}\text { Hughes, } \\
\text { Annmarie; } \\
\text { Meek, Jeff }\end{array}$ & 2014 & Escocia & Costos & $\begin{array}{l}\text { Destaca cómo durante } \\
\text { la guerra, las mujeres, } \\
\text { especialmente las } \\
\text { madres solitarias, } \\
\text { lograron avances } \\
\text { significativos a } \\
\text { través del sistema de } \\
\text { asistencia social. }\end{array}$ \\
\hline 27 & $\begin{array}{l}\text { Illuminating the } \\
\text { darkness, the } \\
\text { impact of the First } \\
\text { World War on cost } \\
\text { calculation practices } \\
\text { in British firms }\end{array}$ & $\begin{array}{l}\text { Boyns, } \\
\text { Trevor }\end{array}$ & 2005 & $\begin{array}{l}\text { Reino } \\
\text { Unido }\end{array}$ & Costos & $\begin{array}{l}\text { Cálculo de costos en } \\
\text { las firmas británicas y } \\
\text { como la contabilidad } \\
\text { de costos surgió en } \\
\text { inglaterra en la Primera } \\
\text { Guerra Mundial }\end{array}$ \\
\hline 28 & Accounting for War & $\begin{array}{l}\text { Chwastiak, } \\
\text { Michele; } \\
\text { Lehman, } \\
\text { Glen }\end{array}$ & 2008 & Mundial & $\begin{array}{l}\text { Historia } \\
\text { general de la } \\
\text { contabilidad }\end{array}$ & $\begin{array}{l}\text { Examina la forma en } \\
\text { la que la contabilidad } \\
\text { ayudó a racionalizar y } \\
\text { normalizar la violencia } \\
\text { y como contribuyó a la } \\
\text { expansión de la guerra. }\end{array}$ \\
\hline 29 & $\begin{array}{l}\text { War, Women and } \\
\text { Accounting: Female } \\
\text { Staff in the UK Army } \\
\text { Pay Department } \\
\text { Offices, } 1914 \text { - } 1920\end{array}$ & Black, John & 2006 & $\begin{array}{l}\text { Reino } \\
\text { Unido }\end{array}$ & $\begin{array}{l}\text { Estudios de } \\
\text { género / Costos }\end{array}$ & $\begin{array}{l}\text { Resalta el papel } \\
\text { pionero de las } \\
\text { mujeres que fueron } \\
\text { empleadas oficialmente } \\
\text { (aunque de manera } \\
\text { temporal) en puestos } \\
\text { administrativos } \\
\text { y contables en } \\
\text { las oficinas del } \\
\text { Departamento de } \\
\text { Pagos del Ejército (APD) } \\
\text { en el Reino Unido de } \\
1914 \text { a } 1920 .\end{array}$ \\
\hline 30 & $\begin{array}{l}\text { A World War II } \\
\text { Cost Accounting } \\
\text { Assignment }\end{array}$ & $\begin{array}{l}\text { Fagerberb, } \\
\text { Dixon }\end{array}$ & 1990 & $\begin{array}{l}\text { Estados } \\
\text { Unidos }\end{array}$ & Costos & $\begin{array}{l}\text { Desarrollo de un } \\
\text { sistema contable } \\
\text { de costos para una } \\
\text { planta de producción } \\
\text { en la segunda guerra } \\
\text { mundial. }\end{array}$ \\
\hline
\end{tabular}

Fuente: Elaboración propia. 


\section{Referencias bibliográficas}

Antonelli, V., D’Alessio, R. y Rossi, R. (2014). Budgetary practices in the Ministry of War and the Ministry of Munitions in Italy, 1915-1918. Accounting History Review, 24, 139-160. doi: 10.1080/21552851.2014.964015

Ariza, S. (2017). Los costos de la guerra versus los dividendos de la terminación del conflicto. Repositorio de la Universidad Libre, Seccional Pereira, 91-100.

Billings, M. y Oats, L. (2014). Innovation and pragmatism in tax design: Excess Profits Duty in the UK during the First World War. Accounting History Review, 24, 83-101. doi: 10.1080/21552851.2014.963951

Black, J. (2006). War, Women and Accounting: Female Staff in the UK Army Pay Department Offices, 1914 - 1920. Accounting, Business \& Financial History, 16(2), 195-218. doi: $10.1080 / 09585200600756225$

Blasco, J., Guzmán, I. y Montoya, J. (2011). La Administración de la Armada española en el siglo XVIII: El caso de la expedición a Argel de 1768 para el canje de cautivos. De Computis, 3-74.

Boyns, T. (2005). Illuminating the darkness the impact of the First World War on cost calculation practices in British firms. Bordeaux: Éditeurs J.G.

Bujaki, M. (2010). Cost-benefit analysis in correspondence related to building the Rideau Canal. Accounting History, 15(2), 402-424. doi: 10.1177/1032373210352373

Cardoni, F. (2014). The 'science' of French public finances in the First World War. Accounting History Review, 24(2-3), 119-138. doi: 10.1080/21552851.2014.967931

Chwastiak, M. (2007). War, Incorporated: Private, Unaccountable and Profitable. Electronic Journal of Radical Organisation Theory, 338-349.

Chwastiak, M. y Lehman, G. (2008). Accounting for War. Accounting Forum, 32(4), 313-326. doi: 10.1016/j.accfor.2008.09.001

Cinquini, L., Gianetti, R. y Tenucci, A. (2016). The making of uniform costing in a war economy: The case of the Uniconti Commission in Fascist Italy. Accounting History, 21(4), 445-471. doi: 10.1177/1032373216652414

Clauso, A. (1993). Análisis documental: el análisis formal. Revista General de Información y Documentación, 3, 11-19. Recuperado el 03 de 11 de 2019, de https://revistas.ucm.es/ index.php/RGID/article/viewFile/RGID9393120011A/11739

Cobbin, P. (2009). The best brains of the public accounting world: the restricted membership of the Army Accountancy Advisory Panel, 1942-1945. Accounting Historians Journal, 36(2), 1-29. doi: 10.2308/0148-4184.36.2.1

Cobbin, P. y Burrows, G. (2010). The British navy's 1888 budgetary reforms. Accounting History, 15(2), 153-172. doi: 10.1177/1032373209359321

Crafts, N. y Mulatu, A. (2004). How did the Location of Industry Respond To Falling Transport Costs in Britain Before World War I? The Journal of Economic History, 66, 1-38. doi: 10.1017/S002205070600026X

Djatej, A. y Sarikas, R. (2009). The Second World War and Soviet accounting. Accounting History, 35-54. doi: 10.1177/1032373208098551

Dubet, A. (2005). Administrar los gastos de guerra: Juan Orry y las primeras reformas de Felipe V (1703-1705). Actas sw la VIII Reunión Científica de la Fundación Española de Historia Moderna (págs. 483-501). Madrid: Fundación Española de Historia Moderna. 
Torres, D. Aproximación a la Literatura de la Contabilidad Militar en la Primera y Segunda Guerra Mundial

Fagerberb, D. (1990). A World War II cost Accounting Assignment. The Accounting Historians Journal, 17(1), 81-88. doi: 10.2308/0148-4184.17.1.81

Fleischman, R. y Marquette, P. (2003). The Impact Of World War Ii On Cost Accounting At The Sperry Corporation. Accounting Historians Journal, 30(2), 67-104. doi:10.2308/01484184.30.2.67

Flesher, D. y Previts, G. (2014). Haskins \& Sells during the First World War and its aftermath. Accounting History Review, 24, 211-225. doi: 10.1080/21552851.2014.963952

Fontana, J. (1982). Historia: Análisis del pasado y proyecto social. Madrid: Ediciones Austral.

Funnell, W. (2003). Accounting for War: Financial Control of the British Army 1846-1899. Nueva Gales del Sur: Accounting and Finance Academic Press.

Funnell, W. (2003). Accounting for War: Financial Control of the British Army 1846-1899. Accounting and Finance Academic Press, 116-117.

Funnell, W. (2005). Accounting on the Frontline: Cost Accounting, Military Efficiency and the South African War. Accounting and Business Research, 35(4), 307-326. doi: 10.1080/00014788.2005.9729997

Funnell, W. (2006). National efficiency, military accounting and the business of war. Critical Perspectives on Accounting, 17(6), 719-751. doi: 10.1016/j.cpa.2004.11.008

Funnell, W. (2008). The 'Proper Trust of Liberty': economical reform, the English constitution and the protections of accounting during the American War of Independence. Accounting History, 13(1), 7-32. doi: 10.1177/1032373207083925

Funnell, W. (2011). Social Reform, Military Accounting and the Pursuit of Economy during the Liberal Apotheosis, 1906-1912. Accounting, Business and Financial History, 21(1), 6993. doi: 10.1080/21552851.2011.548549

Funnell, W. y Walker, S. (2014). Accounting for Victory. Accounting History Review, 24, 57-60. doi: $10.1080 / 21552851.2014 .970799$

Galán, J. (22 de 06 de 2017). Año Fiscal. Recuperado el 20 de 05 de 2020, de Economipedia: https://economipedia.com/definiciones/ano-fiscal.html

Gallhofer, S. y Haslam, J. (2003). Mobilising accounting in the radical media during the First World War and its aftermath: The case of Forward in the context of Red Clydeside. Elsevier, 17(2-3), 224-252. doi: 10.1016/j.cpa.2003.06.009

Garcia, C. (2011). A Brief History of Accounting for Goodwill in Japan and France: War, Tax and Accounting Practice. Gakushuin University Economic Review, 48(1), 45-64. doi: $10.1177 / 1032373217748672$

Giroux, G. (2017). Accounting History and the Rise of Civilization (Vol. II). Nueva York: Bussiness Expert Press.

Gómez, J. (2012). La Nueva Historia: una herencia del pasado. Revista Digital de Historia y Ciencias Sociales, 2-10. Recuperado el 07 de 03 de 2020, de http://www.claseshistoria. com/revista/2012/articulos/gomez-nueva-historia.pdf

Gómez-Juárez de la Torre, F. (2018). Derechos reales en la contabilidad de la Real Armada. Estructura tributaria y particularidades de su aplicación sobre el autoconsumo en el departamento de Cartagena en 1779. De Computis, 94-107.

González, A. (2012). Un Estado militar. España, 1650-1820. Revista de Historia Moderna, 171-175. 
Guzmán, I. (2006). Normativa contable en la armada española durante el periodo 17001850: especial referencia a la administración de provisiones. De Computis, 65-146.

Heier, J. (2010). Accounting for the ravages of war: Corporate reporting at a troubled American railroad during the Civil War. Accounting History, 15(2), 199-228. doi: $10.1177 / 1032373209359325$

Hernández, E. (1982). Las cuentas de Fernan López del Campo, primer factor general de Felipe II, para los reinos de España: 1556-1560 : contribución al estudio de la contabilidad y de la Hacienda Pública en la España del siglo XVI. Madrid, Dinamarca: Comunicación presentada en el Fifth Annual Congress of the European Accounting Association.

Hernández, E. (2015). Aproximación al estudio del pensamiento Contable,. Madrid: Asociación Española de Contabilidad y Administración de Empresas.

Hernández, E. (2015). Cervantes como comisionado y recaudador al servicio de la Real Hacienda. Activos, 21-99. doi: 10.15332/s0124-5805.2015.0024.01

Hernández, R., Fernández, C. y Baptista, P. (2010). Metodología de la investigación. Ciudad de México: McGraw Hill.

Hughes, A. y Meek, J. (2014). State Regulation, Family Breakdown, and Lone Motherhood: The Hidden Costs of World War I in Scotland. Journal of Family History, 364-387.

Ichino, A. y Winter-Ebmer, R. (2004). The Long-Run Educational Cost of World War II. Journal of Labor Economics, 39(4), 57-86. doi: 10.1177/0363199014548826

Ikin, C., Johns, L. y Hayes, C. (2012). Field, capital and habitus: An oral history of women in accounting in Australia during World War II. Accounting History, 17(2), 175-192. doi: $10.1177 / 1032373211434421$

IMECAF. (27 de Septiembre de 2012). ¿Qué es la Contabilidad? Recuperado el 20 de 05 de 2020, de El Blog del IMECAF: https://imecaf.com/blog/2012/09/27/que-es-lacontabilidad/

Kuethe, A. y Andrien, K. (2018). El mundo atlántico español durante el siglo XVII: Guerra y reformas borbónicas, 1713-1796. Bogotá: Editorial Universidad del Rosario.

Lemarchand, Y. (2002). The military origins of the French management accounting model: a return to the mechanisms of accounting change. Accounting History, 7(1), 23-57. doi: $10.1177 / 103237320200700103$

Maltby, J. (2005). Showing A Strong Front: Corporate Social Reporting And The 'Business Case' In Britain, 1914-1919. Accounting Historians Journal, 32(2), 145-171. doi: $10.2308 / 0148-4184.32 .2 .145$

Mayer-Sommer, A. (2010). So many controls; so little control: The case of Isaac Henderson, Navy Agent at New York, 1861-4. Accounting History, 15(2), 173-198. doi: $10.1177 / 1032373209359324$

Miley, F. y Read, A. (2012). The implications of supply accounting deficiencies in the Australian Army during the Second World War. Accounting History Review, 22, 73-91. doi: 10.1080/21552851.2012.653131

Miley, F. y Read, A. (2014). Cartoons as alternative accounting: front-line supply in the First World War.Accounting History Review, 24, 161-189. doi: 10.1080/21552851.2014.967932

Miley, F. y Read, A. (2016). The purgatorial shadows of war: accounting, blame and shell shock pensions. Accounting History, 22(1), 5-28. doi: 10.1177/1032373216656648 
Torres, D. Aproximación a la Literatura de la Contabilidad Militar en la Primera y Segunda Guerra Mundial

Moreno, S. (2014). Evaluación general de los periodos históricos de la contabilidad y aplicaciones iniciales en Colombia. Activos, 12(22), 153-169. doi: 10.15332/s01245805.2014.0022.06

Pedrosa, S. (24 de 06 de 2017). Ejercicio contable. Recuperado el 20 de 05 de 2020, de Economipdia: https://economipedia.com/definiciones/ejercicio-contable.html

Porto, J. y Merino, M. (01 de 01 de 2009). Definición de Ejército. Recuperado el 20 de 05 de 2020, de Definición.de: https://definicion.de/ejercito/

Quinche, F. (2006). Historia de la contabilidad: una revisión de las perspectivas tradicionales y críticas de historiografía contable. Revista Facultad de Ciencias Económicas, 187 - 201. Obtenido de http://www.redalyc.org/pdf/909/90900110.pdf

Quinn, M. y Jackson, W. (2014). Accounting for war risk costs: management accounting change at Guinness during the First World War. Accounting History Review, 191-209. doi: 10.1080/21552851.2014.96

Ríos, M. (2009). De la historia de las mentalidades a la historia cultural. Notas sobre el desarrollo de la historiografía en la segunda mitad del siglo xx. Estudios de Historia Moderna y Contemporánea de México, 37, 97-137. doi: 10.22201/ iih.24485004e.2009.37.15309

Rocha, M. y Martínez, I. (2016). Historia de la educación contable en Colombia: la aparición de las primeras escuelas y facultades de Contabilidad. Activos, 14(26), 101-122.

Rutterford, J. y Walton, P. (2014). The war, taxation and the Blackpool Tower Company. Accounting History Review, 24, 103-117. doi: 10.1080/21552851.2014.963954

Scorgie, M. y Reiss, J. (1997). The impact of naval experience on accounting in colonial Australia from 1788 to 1792. Accounting History, 2(2), 53-76. doi: 10.1177/103237329700200205

Suárez, J. (2011). El campo contable en el proceso de la independencia de Colombia (17801830). Lúmina, 194-241.

Talbot, P. (2010). Colonel William Henry Sykes: His contribution to statistical accounting. Accounting History, 15(2), 253-276. doi: 10.1177/1032373209359332

Torres, R. (2013). El precio de la guerra: El Estado fiscal-militar de Carlos III (1779-1803). Madrid: Marcial Pons Ediciones de Historia.

Tyson, T. y Fleischman, R. (2006). Accounting for interned Japanese-American civilians during World War II: Creating incentives and establishing controls for captive workers. Accounting Historians Journal, 33, 167-202. doi: 10.2308/0148-4184.33.1.167

Vollmers, G., Antonelli, V., D’Alessio, R. y Rossi, R. (2015). Cost Accounting for War: Contracting Procedures and Cost-plus Pricing in WWI Industrial Mobilization in Italy. European Accounting Review, 25(4), 1-53. doi: 10.1080/09638180.2015.1085887

Walker, S. (2017). Accountants and the pursuit of the national interest: A study of role conflict during the First World War. Elsevier, 47, 8-25. doi: 10.1016/j.cpa.2017.01.001

Wooton, C. y Spruill, W. (2014). The role of women in Major Public Accounting Firms in the United States during World War II. Business and Economic History, 23(1), 241-252. doi: 10.1006/cpac.1995.1033 